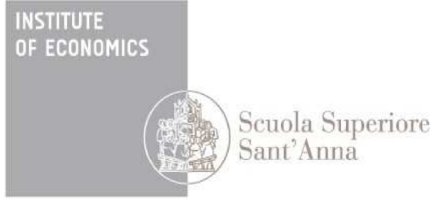

LEM | Laboratory of Economics and Management

Institute of Economics

Scuola Superiore Sant'Anna

Piazza Martiri della Libertà, 33 - 56127 Pisa, Italy ph. +3905088.33 .43$

institute.economics@sssup.it

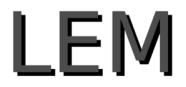

Working Paper Series

\title{
Systemic Risk, Contagion, and Financial Networks: A Survey
}

\author{
Matteo Chinazzi * \\ Giorgio Fagiolo *
}

*Institute of Economics and LEM, Scuola Superiore Sant'Anna, Pisa, Italy 


\title{
Systemic Risk, Contagion, and Financial Networks: a Survey
}

\author{
Matteo Chinazzi* Giorgio Fagiolo ${ }^{\dagger}$
}

June 4, 2015

\begin{abstract}
The recent crisis has highlighted the crucial role that existing linkages among banks and financial institutions plays in channeling and amplifying shocks hitting the system. The structure and evolution of such web of linkages can be fruitfully characterized using concepts borrowed from the theory of (complex) networks. This paper critically surveys recent theoretical work that exploits this concept to explain the sources of contagion and systemic risk in financial markets. We taxonomize existing contributions according to the impact of network connectivity, bank heterogeneity, existing uncertainty in financial markets, portfolio composition of the banks. We end with a discussion of the most important challenges faced by theoretical network-based models of systemic risk. These include a better understanding of the causal links between network structure and the likelihood of systemic risk and increasingly using the empirical knowledge about real-world financial-network structures to calibrate theoretical models.
\end{abstract}

Keywords: Systemic Risk, Contagion, Complex Networks, Resilience, Connectivity, Robust-yet-Fragile Networks, Financial and Economic Crisis.

JEL Classification: G01, G20, G32, C63

\section{Introduction}

In the recent years, the issue of resilience of financial systems has occupied center stage in both theoretical and applied research (Allen and Babus, 2009; Hasman, 2012). After the events that culminated with the bankruptcy of Lehman Brothers on September 15, 2008, it has become increasingly clear that in order to explain

\footnotetext{
*Sant'Anna School of Advanced Studies (Pisa) - Italy. E-mail: matteo@chinazzi.com

†Sant'Anna School of Advanced Studies (Pisa) - Italy. E-mail: giorgio.fagiolo@sssup.it
} 
phenomena such as contagion and systemic risk in financial markets, new methodologies able to address the deep causes of structural vulnerability of the financial sector were needed (Haldane, 2009, Catanzaro and Buchanan, 2013).

One of the main ideas around which some consensus has been emerging concerns the foremost importance of the interaction structure among banks and financial institutions in channeling and amplifying shocks hitting any single agent in the system (May et al., 2008). In other words, what happens at the aggregate level, i.e. the extent and depth of contagion, may be strongly related to the topology of the web of relationships linking banks and financial institutions in the system Caldarelli et al. 2013). A better understanding of such a structure should therefore help us in evaluating systemic risk and predicting the aggregate impact of liquidity shocks.

To address these fundamental issues, network theory becomes central (Schweitzer et al. 2009). Indeed, the web of relationships between the main actors of the financial sector (e.g., the interbank market) can be represented as a graph (i.e., a network) where banks are the nodes and edges represent the existence of credit/lending relationships between any two parties. The weight of each edge might be proportional to the magnitude of the exposure between two institutions, while edge directionality may allow us to determine who is the creditor and who is the lender. Network theory allows one to statistically characterize the structure of such graphs and taxonomize them according to their similarity or dissimilarity features (Caldarelli, 2007, Newman, 2010; Jackson, 2010).

A sensible question therefore regards the way in which different classes of topological structures map into higher or lower systemic risk and resilience. This paper surveys recent theoretical work that has been trying to recast this issue in terms of network connectivity. In other words, we focus on a simple research question: does a more connected banking network imply a more stable and resilient financial sector? In particular, we examine simple models that have been trying to explain the robust-yet-fragile property of the system: i.e. why connections can serve at the same time as shock-absorbers and shock-amplifiers. One of the main result is that, when the network is not too much connected, the higher the connectivity of the system, the higher risk-sharing and diversification. However, above a certain connectivity threshold, those connections that before served as a mutual insurance against shocks, can now act as mutual incendiary devices (Haldane, 2009).

We discuss how the relevant literature has tried to explain the various ways in which bank and market characteristics - such as bank heterogeneity, moral hazard, imperfect information, changes in asset prices, and capital and liquidity requirements - interact with network connectivity in determining the stability of the financial 
system. More specifically, we focus on theoretical models that aim to describe and explain how contagion and default cascades might propagate when a financial system is hit by a negative shock (e.g. high demand for liquidity or a sudden default of a bank) ${ }^{1}$

The survey is structured as follows. In section 2, we introduce some very stylized theoretical models that explain how, in a minimal setting, connectivity can determine stability or instability of the financial system. Section 3 focuses on more sophisticated and recent contributions that apply tools stemming from network theory to explain how the robust-yet-fragile property of the system can emerge in interbank networks. In section 4, we study the role played by heterogeneity in influencing systemic resilience, while in section 5, we analyze what happens when we introduce some more realistic assumptions regarding the structure of information available to the agents and the incentives to misbehave that banks might have. We also discuss how, by endogeneizing asset prices and adding capital and liquidity requirements, one can affect the probability and extent of contagion (section 6). Finally, section 7 comparatively discusses pros and cons of the main classes of models analyzed in the survey, and concludes with an appraisal of some of the most relevant research challenges ahead.

\section{Connectivity, Coordination and Network forma- tion}

For a bank, holding interconnections with other banks always implies dealing with the trade-off between risk sharing and risk of contagion. Indeed, more interconnected balance sheets imply that a negative shock, say a liquidity shocks, can be more easily dissipated and absorbed when a bank has multiple counterparties to whom discharge the negative hit. Additionally, connectivity may induce banks to bail out each other in order to prevent contagion, therefore avoiding the intervention of a central planner. However, on the flip side of the argument, a well connected bank will also have a higher probability of being hit by a negative shock through one of its neighbors. Therefore, studying the role of the level and form of connectivity in the interbank credit market is crucial to understand how direct contagion works, i.e. how an idiosyncratic shock may travel through the network of banks and affect the balance sheets of multiple agents.

\footnotetext{
${ }^{1}$ We do not cover here the empirical studies done on this subject. We refer the interested reader to the works of Upper (2011) and Hasman (2012) for more details on this stream of (applied) literature.
} 


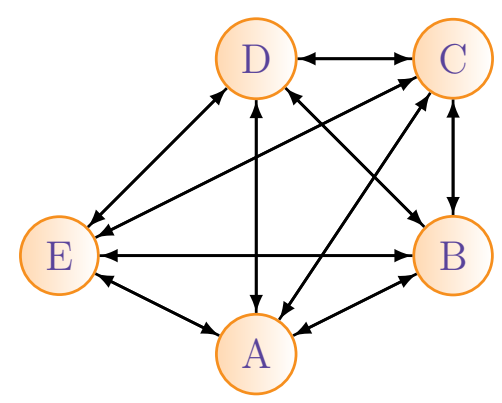

Figure 1: Directed complete graph: a network in which edges are directed and all nodes are connected to each other.

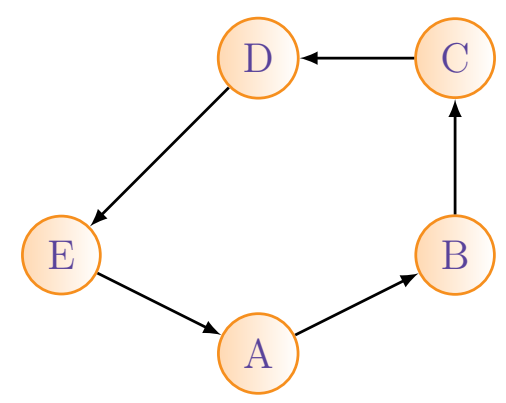

Figure 2: Directed cycle graph: a network where edges are directed and nodes are connected in a way that they form a single cycle (i.e. vertices are connected in a closed chain).

Early contributions have explored this issue employing three main types of network structures: directed complete graphs, directed cycle graphs and partitioned graphs. A directed complete graph is a network in which edges are directed and all nodes are connected to each other (see Figure 1). A directed cycle graph, instead, is a network where edges are directed and nodes are connected in a way that they form a single cycle (see Figure 2). In other words, some number of vertices are connected in a closed chain. A partitioned graph is a network where some nodes are not connected (not even indirectly) with all the other nodes (see Figure 3).

Allen and Gale (2000) seminal work is probably the most well-known contribution on the analysis of contagion through direct interbank credit linkages. In their minimal setting, only four banks are present. Each bank is located in a different region and liquidity shocks are deemed to be negatively correlated across regions. Different demands for liquidity are caused by the presence - in different fractions - of different types of consumers. Following Diamond and Dybvig's preferences (Diamond and Dybvig, 1983), agents are of two types: early-consumers and lateconsumers. In particular, assuming that only three time periods $t \in\{0,1,2\}$ exist, early-consumers prefer to consume their good at $t=1$ while late-consumers prefer 


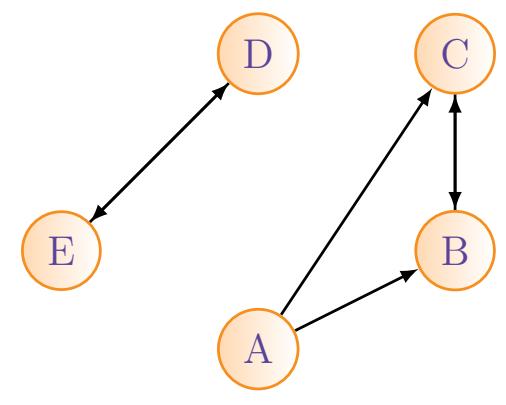

Figure 3: Directed partitioned graph: a network where some nodes are not connected (not even indirectly) with all the other nodes.

$t=2$. However, at $t=0$ their type is not known since the number of the two types of customers fluctuates randomly across regions albeit the aggregate demand for liquidity remains constant. In this context, banks cannot perfectly forecast the total demand for liquidity they will observe at times $t=1$ and $t=2$. This generates an incentive for creating an interbank market to exchange deposits at time $t=0$, before banks observe the shocks. Regions with liquidity surpluses will provide resources to banks in regions with liquidity shortages provided that shocks are negatively correlated across regions. To study contagion, the authors observe what might happen in different network configurations when there exists an excess demand for liquidity at the aggregate level. From a network theory perspective, they consider directed weighted graphs where all edges have the same weights and linkages represents cross-holdings of deposits in different regions.2 A non-monotonic relationship between completeness and incompleteness of markets is found. In particular, in the case of the directed complete graph, contagion is restricted to only one region, whereas in the case of the directed cycle graph the crisis extends to all regions. Finally, in the case of the partitioned graph structure contagion affects only two out of four regions.

An extension of Allen and Gale's model is provided in Babus (2005). They study what happens when banks endogenously decide the amount of deposits they are going to exchange in the interbank market. Also, liquidity shocks are not necessarily negatively correlated across regions. They consider the case where there are six regions (and hence banks) in total and $\left(\begin{array}{l}6 \\ 3\end{array}\right)$ possible states of the world. In each state of the world, three regions will suffer a high liquidity shock while the other regions will face low liquidity demands. Additionally, banks are affected by an idiosyncratic shock that with a small probability will cause them to default. In terms of network

\footnotetext{
${ }^{2} \mathrm{~A}$ weighted network is a graph where links are given positive weights that represent the strength of bilateral interactions. In weighted directed network, the weight of the directed link $i \rightarrow j$ may be different from the weight of the link $j \rightarrow i$.
} 


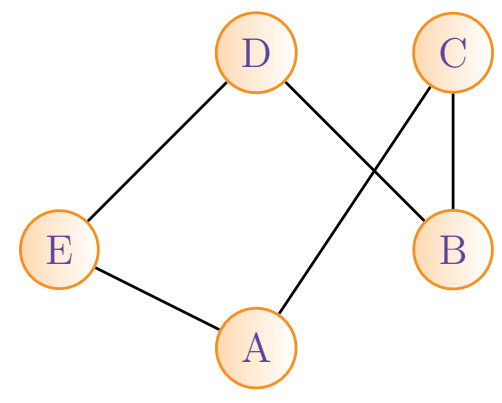

Figure 4: Undirected $k$-regular graph (example with $k=2$ ): a network where all nodes have the same degree $k$.

structures, they analyze what happens only in undirected $k$-regular weighted graphs, that is in networks where all nodes have the same degree $k$ (see Figure 4), a link exists if two banks exchange deposits at time $t=0$ and edge weights - representing the amount of deposits exchanged - are endogenously chosen ${ }^{3}$ They assume incomplete information regarding the network configuration. Therefore, when the network is incomplete, there would be two sources of uncertainty. First, banks will not know how many of their neighbors are affected by high liquidity demand shocks. Second, they will not know how many links there exist connecting them with banks of different types, that is with banks that face a liquidity shock different than the one they observe. Instead, in a complete graph, the only uncertainty would regard the types of one's own neighbors. The main result is that banks will allocate their deposits to minimize the loss of value they will incur when one of theirs neighbors is liquidated assuming that the worst case scenario occurs. Additionally, in incomplete networks, the allocation which is ex-ante optimal is found to be ex-post sub-optimal for any realization of the state of the world with except to the worst case scenario. On the contrary, in a complete network, ex-ante and ex-post optimality coincide since the worst case scenario is realized for any distribution of the liquidity shocks. As a consequence, an incomplete network is not only more risky in terms of systemic risk - as already found in Allen and Gale (2000) - but decisions made by banks in terms of their exposures are (ex-post) sub-optimal.

Another interesting extension of the basic framework of Allen and Gale (2000) is instead explored in Babus (2007). In this model, the link formation process is endogeneized and the network is an undirected binary graph where an edge exists only when two banks decide to exchange deposits at time $t=0$. The assumptions are the same as in the previous model, with just a few differences: there are $2 n$ regions

\footnotetext{
${ }^{3}$ In a directed network, the in-degree (respectively, out-degree) of a node is defined as the number of incoming (respectively, outcoming) links of a given node. The degree of a node is simply the sum of its in-degree and out-degree, i.e. the total number of links of a node.
} 


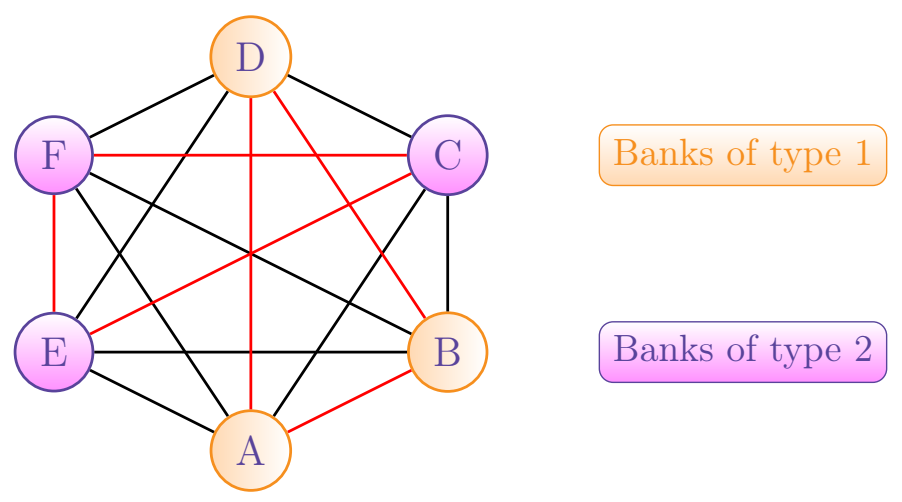

Figure 5: Complete bipartite graph: a network in which there are two types of nodes and each node is connected to all node of type different than its own. Black edges are given, red edges are determined endogenously

(and hence banks), instead of just six regions (and banks) and liquidity shocks are negatively correlated between regions in a predetermined way. As a consequence, there is no uncertainty caused by the absence of a precise correlation structure of the shocks. In order to simplify the model, the author also assumes that the network formation game is played only between banks of the same type. Instead, banks of different types are assumed to be connected as a complete bipartite graph. That is, each bank is connected to all banks of type different than its own (see Figure 5). Given the information about the correlation structure of the shocks, banks can fully insure against liquidity fluctuations and therefore they need only to prevent losses through contagion. Each bank will choose a network structure where the loss of value they will incur on their deposits when one of theirs neighbors is liquidated is minimized and the loss should not be higher than the maximum amount of the illiquid asset each bank can liquidate without going bankrupt. If that were not the case, each bank would have been better off by staying out of the interbank market. The limit loss is identical for each bank and it is independent of the number of links a bank has. Instead, it depends on the average fraction of early consumers present in the system, which in turn depends on the probabilities of observing early and late consumers in the population. By using the notion of bilateral equilibrium (as introduced in Goyal and Vega-Redondo, 2007), the author shows that the network structures which emerge in equilibrium are very likely to support systemic stability, with a probability of contagion that goes to zero as the number of banks increases. Furthermore, the completeness of the graph is just a sufficient condition for stability, not a necessary one. Indeed, most of the networks turn out to be incomplete.

In order to explore the role played by the type of uncertainty in driving the main results, Freixas et al. (2000) use a similar setting as in Allen and Gale (2000) 
but assume that the source of uncertainty is not when agents consume but where they are going to consume. Consumers have different preferences with respect to where they are going to be when it is time to consume. There are two types of risk-neutral consumers: travelers who consume in other locations and non-travelers who consume only in their home location. Travelers, if an interbank market is not in place, will withdraw their money at period $t=1$ - when they discover their type - and carry it to another region. In essence, in this setting, we have a space-coordination problem, not a time-coordination problem as in Allen and Gale (2000). In this case, banks can decide to create credit lines that give the right to a travel customer coming from, for instance, region $i$ to withdraw when she is in another region $j$, the place where she is planning to consume. Once again, from a network theory standpoint, we are dealing with directed weighted graphs where linkages represent cross-holdings of deposits in different regions. Such credit lines are the mechanism through which contagion can be transmitted in case a bank is notsolvent. Insolvency is caused by the fact that banks also invest in risky projects that may provide a cash flow which is not sufficient to repay the contractual obligation they have with their customers. Therefore, a negative exogenous shock on the risky investments may lead to insolvency and contagion. Three possible configurations of the interbank market are studied: the credit chain interbank funding case (i.e. a directed cycle graph), where consumers are located around a circle with travelers moving to their clockwise adjacent location (as in Salop's model, see Salop, 1979); the diversified lending case (i.e. a directed complete graph), where travelers spread uniformly in all locations and the autarkic case (i.e. all nodes are isolated vertices), when banks do not have open credit lines with banks in other regions. Notice that credit flows will be in the direction opposite to agents' movements. Considering what would happen under the different configurations it emerges that, in the diversified case, an insolvent bank is able to share more of its losses with its neighbors. As a consequence, interbank connections allow the system to be more resilient to defaults. However, on the flip side, this also means that market discipline is weakened in the diversified case compared to the credit chain network case since an insolent bank might be able to survive. In the credit chain network, instead, a smaller loss can trigger contagion with respect to what would happen in the diversified case. Additionally, the diversified lending configuration is always stable when the number of banks is large enough, while additional nodes have no impact on the stability of the credit chain structure. Lastly, the autarkic configuration is proven to be the safest option. However, in autarky, banks will invest fewer money on the risky assets and efficiency would be lower compared to having open credit lines with banks. 


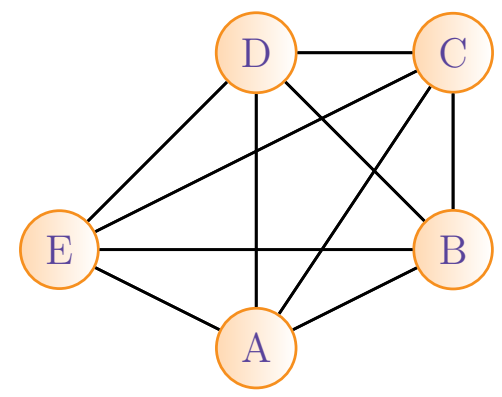

Figure 6: Undirected complete graph: a fully linked network.

Therefore, there is a trade-off between having a risky interbank credit market and a safe autarkic payment mechanism that foregoes investment opportunities.

Another possible source of uncertainty concerns the initial endowment of money that each bank receives. In order to investigate whether this may have an effect in the trade-off that exists between risk-sharing and risk of contagion in the design of an optimal interbank network, Leitner (2005) assumes that at $t=0$ each bank needs to have an endowment of at least one unit of good in order to be able to invest. Otherwise, it would be impossible to invest in the project. Therefore, in this context, we have an undirected binary graph where a link exists between two agents when they can transfer endowments among themselves and a negative liquidity shock would mean observing an endowment smaller than one. Additionally, the project itself will produce a cash flow only if the investing bank and all its neighbors are investing one unit of good in the project. As a consequence, being part of an interbank market has two effects: on one side, a bank hit by a negative liquidity shock can use its connections to collect enough resources to allow itself to invest in the project; on the other side, a negative shock affecting just one neighbor, preventing it from investing in the project, will also cause all its neighbors to default. It also means that when agents are not linked together, only the one who realizes high endowments will invest and they will not have any incentive in helping unfortunate banks. Instead, when a connection is indeed present, the same agent will help their neighbors, otherwise all projects will fail by contagion. Therefore, an incentive will exist for safe banks to bail out troubled banks, without any action from the controlling authority. In order to make the constraints more binding, the author also assumes that banks cannot commit ex-ante to: (i) pay out of their initial endowments; (ii) pay out of their projects' cash flows; and (iii) invest in their projects. That is, we are in the extreme situation where agents cannot commit to pay anything and where they will invest on their projects only if they can succeed (i.e. if their connected neighbors are investing too). The result is that even linkages 
that create the threat of contagion can be optimal. Coordination, in this case, will be achieved through a central planner who proposes an optimal allocation of the endowments and an optimal investments vector to the banks. Then, agents decide whether to accept or reject the proposal which would be executed only if all agents accept. Otherwise, if at least one of them refuses, no transfers are made and agents remain in autarky. The results they obtain are that: ex-ante, a fully linked network (i.e. undirected complete graph, see Figure 6) Pareto dominates an unlinked network (i.e. all nodes are isolated) if the probability that - by pooling all available resources together - all projects could be financed is higher than the probability that a generic bank has to be able to finance a project on its own. However, ex-post, an unlinked network is better than a fully linked network if and only if the realization of the endowments is such that their sum is smaller than the number of banks but there exists at least one agent with endowment higher than one. The reason being that in a fully linked network no investments will take place, while in the unlinked network at least the agent with endowment greater than one will invest. Moreover, also intermediate network structures - i.e. partitioned graphs - are possible and the probability of adding an additional bank to an existing group is found to depend non-monotonically on the probability of observing negative liquidity shocks. It is possible that when the probability of a shock increases, the disadvantage of adding an agent actually decreases. Lastly, when endowments are identically and independently distributed, it is always the case that for a sufficiently large number of banks, the system converges to optimality with a fully linked network whenever the expected individual amount available for investments is greater than one.

Glasserman and Young (2015) analyze contagion using a full-fledged shock distribution and they estimate how much of the losses are directly linked to network connectivity by comparing two different scenarios: in one case the financial system is a connected system; in the alternative scenario all connections among financial institutions had been removed. The main result of this work is that the authors are able to derive useful bounds on the financial systemâĂŹs susceptibility to contagion without knowing the exact details of the system's topology. The starting point consists in taking the balance sheets of individual banks as a given and then estimate how balance sheets' characteristics contribute to exacerbate systemic risk after the initial shocks to asset values. For example, by determining whether network shocks are more important than (possibly external) shocks to asset values in increasing the probability of default of a specific node. In Glasserman and Young (2015) model the agents are: the investors (i.e. the financial institutions which are the nodes of the network), households and non-financial firms. Financial institutions can lend 
and borrow to all the agents. Therefore, the connectivity exists within the interbank market but also between investors and outside agents. Financial contagion is then studied in two different configurations: one in which links can exists among all agents, and another in which links exist only with agents outside the financial sector (i.e. a bank can lend/borrow money only to/from households and/or non-financial firms). The same shock distributions are then applied to both systems. As a result, the authors can quantify the role of network connections in determining the number of defaults in the system by comparing the outcomes in the two configurations. They measure what proportion of the losses observed after a systemic shock can be attributed to connections between institutions as opposed to characteristics of individual banks. The basic setup of the model is the same as in Eisenberg and Noe (2001) and it comprises three main components: a set of $N$ nodes (i.e. the banks/investors), an $N \times N$ liabilities matrix $P$ where $p_{i j}$ represents the payment due by node $i$ to node $j$, and a vector $c$ where $c_{i}$ represents the value of outside assets held by node $i$ in addition to its claims on other nodes in the network. System risk is studied along two different dimensions: probability of contagion, i.e. the probability that a given set of nodes $D$ will default after some initial shocks; and amplification of contagion, i.e. the value of the losses occurred conditional on having observed $D$ defaults. Glasserman and Young (2015) find that direct losses are not the main source of contagion. Instead, in order to have systemic-wide default cascades, the network structure is crucial in amplifying the effects of an initial counter-party loss. That is, indirect contagion is frequently more important than direct contagion. Furthermore, contagion is always weak, irrespective of the structure of the interbank network, if heterogeneity is not present. In addition, the authors find that the total expected losses in a financial system relative to the total expected losses in an otherwise equivalent system of isolated nodes - regardless of the network structure - are bounded by the maximum financial connectivity over all nodes in the network. The authors are able to estimate what are the bounds of the amplification effects given a measure of financial connectivity. Network topology becomes more important for both contagion (direct losses) and amplification (indirect losses) once bankruptcy costs and marked-to-market reductions in credit quality are introduced: bankruptcy costs steepen the losses at defaulted nodes, therefore increasing the likelihood that defaults will spread to other nodes; instead, a reduction in credit quality deteriorates the asset values of a node in advance of a default event, with the consequence that a system-wide default cascade can be triggered solely by a loss of confidence rather than an actual default. 


\section{Connectivity and Phase Transitions}

In order to explain the robust-yet-fragile tendency that the financial systems exhibit, a good starting point is to develop simple but formal (analytical) models that can explain phase transitions in contagion occurring when connectivity and other properties of the network vary.

A perfect example of such an approach is the model in Gai and Kapadia (2010). The authors study how the probability and potential impact of contagion is influenced by aggregate and idiosyncratic shocks, network topology and liquidity. The framework employed adopts techniques and concepts coming from the literature of complex networks (e.g. Callaway et al., 2000, Newman et al., 2001, Strogatz, 2001, Watts, 2002; Newman, 2003) and uses numerical simulations to illustrate and clarify the analytical results obtained. The authors find that the financial system exhibits a robust-yet-fragile tendency. Even when the probability of contagion is very low, its effects can have widespread consequences. Higher connectivity reduces the probability of default when contagion has not started yet. However, when contagion begins, higher connectivity increases the probability of having large default cascades.

The model portrays $N$ financial intermediaries (i.e. banks), randomly linked together in a directed weighted network where link weights represent interbank liabilities. Balance sheets of banks are formally modeled and they include, for a generic bank $i$, interbank assets (denoted by $A_{i}^{I B}$ ) and liabilities $\left(L_{i}^{I B}\right)$, illiquid assets $\left(A_{i}^{M}\right.$, e.g. mortgages) and deposits $\left(D_{i}\right.$, exogenously determined). As an additional simplifying assumption, total interbank asset positions are assumed to be evenly distributed among all incoming links (i.e. risk sharing is maximized). A bank is solvent if and only if:

$$
(1-\phi) A_{i}^{I B}-q A_{i}^{M}-L_{i}^{I B}-D_{i}>0
$$

where $\phi$ is the fraction of banks with obligations to $i$ that have defaulted and $q$ is the resale price of the illiquid asset (with $q \in(0,1]$ ). Furthermore, a zero recovery assumption is made: when a bank fails, all its interbank assets are lost.

Contagion is modeled by randomly defaulting a node in the network and then observing whether a chain reaction starts. Initially, all banks are solvent and defaults can spread only if the banks neighboring a defaulted node are vulnerable. By definition, a bank is vulnerable whenever the default of one of its neighbors causes a loss to its balance sheet such that the solvency condition is no more met. Vulnerability crucially depends on the capital buffer of the bank, which is defined as $K_{i} \equiv A_{i}^{I B}+A_{i}^{M}-L_{i}^{I B}-D_{i}$, and on the in-degree of the node. 
Define a vulnerable cluster as the set of banks reached following an outgoing link from a vulnerable bank to its end and then to every other vulnerable bank reachable from that end. Phase transitions occur when the average size of the vulnerable cluster diverges. In particular, phase transitions happen only for intermediate values of average degree and when the initial defaulting bank is within one degree of separation of the vulnerable cluster. Let $\bar{z}$ be the upper bound for the node-average degree $z$ when the phase transition still occurs and $\underline{z}$ be the lower bound. Then, the probability of contagion (i.e. the probability of the average vulnerable cluster size to diverge) is found to depend non-monotonically in $z \in[\underline{z}, \bar{z}]$ : for low values of connectivity, the higher $z$, the higher is the probability of contagion and larger the size of the vulnerable component, i.e. risk-spreading effects prevail. For high values of connectivity, instead, the risk-sharing effect prevails. Indeed, when $z$ is too low (i.e. $z<\underline{z}$ ), the network is insufficiently connected to spread contagion. On the contrary, when $z$ is too high (i.e. $z>\bar{z}$ ), the probability that a bank is vulnerable is too small and contagion cannot spread since there are too many safe banks. When $z$ is very close to $\bar{z}$, the system exhibits a robust-yet-fragile tendency, with contagion occurring rarely but spreading very widely when it does take place. In addition, once the assumption on the uniform distribution of incoming links is withdrawn, the authors show that their main results still hold, with the only difference that the window-of-contagion becomes wider since an uneven distribution of exposures makes banks more vulnerable to the default of some of their counterparties for higher values of $z$ than it would have been otherwise. Finally, numerical simulations show that lowering capital buffers both widens the contagion window and increases the probability of contagion for fixed values of $z$. Also, when liquidity risk is added i.e. the price of the illiquid asset is allowed to vary - both contagion window $[\underline{z}, \bar{z}]$ and the extent of contagion widen.

In Gai and Kapadia (2010) model, shocks hitting the system were homogeneous in size. However, intuition suggests that another possible source of phase transitions in contagion models can come from the size of the shock. In order to address this point, Acemoglu et al. (2013) use a model where the size of the shock is linked to the total excess liquidity of the system. They employ a framework where there are again three time periods and $N$ financial institutions (i.e. banks). Banks observe an initial random endowment $e$ and they can invest in a project that requires $e$ units of capital. However, agents cannot use their own financial resources to invest but they need to borrow them. Furthermore, lending and borrowing opportunities are constrained in the sense that a generic bank $i$ can borrow only a given maximum amount of money from a bank $j$ and this relationship does not need to be symmetric. 
The entire set of such constraints is described by a directed weighted graph where each edge weight represents this opportunity constraint. Borrowing and lending decisions are endogenously determined by the agents and a bank can also decide to borrow from outside financiers. Therefore, the existence of a link does not imply that a lending agreement is indeed active.

The project can be liquidated prematurely at a loss or kept until maturity to $t=2$. Once a bank invests in a project, it will also be accountable for an additional external obligation that must be paid with priority over the other obligations. Stability and resilience of the financial system are defined respectively as the inverse of the expected number of defaults and the inverse of the maximum number of possible defaults. In terms of network structures, they study what happens in regular a directed weighted complete graph, in a regular directed weighted cycle graph and in a $\gamma$-convex combination of the two. That is, a graph where the resulting weighted adjacency matrix can be obtained as a linear combination of the complete and cycle graphs. As far as the size of the shocks are concerned, they consider two cases. One in which a small shock hits the system and one in which a large shock hits the system. A shock is considered small if its size is smaller than the total excess liquidity present in the system 4 When a small shock hits the system, the cycle graph turns out to be the least resilient and least stable network, whereas the complete graph is the most resilient and most stable. A convex combination of the two becomes less stable and less resilient as $\gamma$ increases (the higher the $\gamma$, the closer the graph is to the cycle network configuration). Conversely, when the shock is large, the complete and cycle graphs are the least stable and least resilient financial networks. The authors also find that for small values of $\delta$ in any $\delta$-connected financial network 5 the system is strictly more stable and resilient than the cycle and complete configurations.

Such a phase transition occurs because two different shock absorbers interplay when negative liquidity shocks hit the system. The first shock absorber is excess liquidity of non-distressed banks, i.e. a negative shock is attenuated once it reaches banks with excess liquidity. The second absorber concerns the fact that, in weakly connected graphs (as the ones implied by the $\delta$-connected networks), senior creditors can be forced to bear a greater proportion of losses, limiting the spread of contagion. As a consequence, when a shock is large - i.e. the total excess liquidity is insufficient

\footnotetext{
${ }^{4}$ That is, smaller than the product of the number of banks present in the model times the difference between the cash flows obtained from the investments and the amount of the obligations that needed to be paid which are associated with the investment in the project. Instead, if the opposite holds, the shock is considered to be large.

${ }^{5} \mathrm{~A}$ financial network is defined to be $\delta$-connected if it contains a collection of banks $M \subset N$ for which the total obligations of banks outside $M$ to any bank in $M$ is at most $\delta \geq 0$ and the total obligations of banks in $M$ to any bank outside of $M$ is no more than $\delta$.
} 
to contain it - the second mechanism of absorption comes into play and creates the phase transition.

Furthermore, the authors also consider what would happen if instead of having a single shock, multiple (identical) shocks hit the network. In such a case, a shock is defined to be small if its size is lower than total excess liquidity divided by the number of shocks and it is considered large otherwise. With multiple shocks, equilibrium regimes also depend on two threshold values for the total interbank liabilities and claims: a lower bound $\underline{\epsilon}>0$ and an upper bound $\bar{\epsilon}>\underline{\epsilon}$. If shocks are small and interbank liabilities and claims are above $\bar{\epsilon}$, the complete graph would be the most stable and resilient while the cycle graph would be the least stable and resilient. If shocks are large, when interbank liabilities and claims are above $\bar{\epsilon}$ complete and cycle graphs would be the least stable and resilient, while the $\delta$-connected system would be strictly more stable than the complete and cycle cases when $\delta$ is small. Conversely, when interbank liabilities and claims are above $\underline{\epsilon}$ but below $\bar{\epsilon}$, the cycle graph would be the most stable and resilient, while the complete one would be the least stable and resilient. This last (new) result suggests that - in such specific parameterization - claims of senior creditors will be used more effectively as a shock absorption mechanism in the cycle graph than in the complete graph.

Finally, the model allows for an investigation of the consequences of endogeneizing lending decisions. This is done by permitting agents to determine the structure and terms of their bilateral interbank agreements. As far as efficiency is concerned, results suggest that banks are not able to internalize the effects that their lending decisions have on agents different than their immediate creditors. Therefore, since such financial network externality cannot be internalized by banks, optimal graphs are either too sparsely or too densely connected as compared to what would have been socially efficient. In addition, a second form of phase transition takes place. When long-term returns from the investment project are made partially pledgeable above a given threshold, there are no network effects on contagion since the excess liquidity within the system can be efficiently reallocated to distressed banks. Therefore, regardless of the network structure of the financial system, no defaults will occur.

In a following contribution, Gai et al. (2011) show how tipping points (i.e. phase transitions) can exist also in a model that studies the resilience of the financial system to liquidity shocks. In particular, the model used still portrays $N$ banks randomly linked together in a directed weighted network. However, the composition of the balance sheets is now different. The assets side still includes illiquid assets (now called fixed assets), (unsecured) interbank assets, and fully liquid assets $\left(A_{i}^{L}\right)$ 
but - in addition - it also comprises assets that can be used as collateral in sale-andrepurchase-agreement (i.e. a repo) transactions $\left(A_{i}^{C}\right)$ and reverse repo assets (i.e. collateralized lending, $\left.A_{i}^{R R}\right)$. On the liability side, along with deposits, interbank liabilities and capital we also have repo liabilities (i.e. borrowing secured with collateral, $\left.L_{i}^{R}\right)$.

Repo financing can be obtained either using fully liquid assets as collateral (with no haircut) or by using collateral assets (with haircut). In particular, the maximum amount that can be borrowed when using only collateral assets is equal to $(1-h-$ $\left.h_{i}\right) A_{i}^{C}$ where $h$ is an aggregate haircut, while $h_{i}$ is a bank-specific haircut that might reflect the idiosyncratic probability of default of bank $i$. Lastly, illiquid assets and interbank assets cannot be used as collateral. The maximum amount that can be borrowed when using rehypothecated reverse repo assets is equal to $\left[\left(1-h-h_{i}\right) /(1-\right.$ $h)] A_{i}^{R R}$ since reverse repo assets can be used in another repo transaction.

Contagion is triggered exogenously either via bank-specific liquidity shocks, or via a shock to the aggregate (i.e. $h$ ) or the idiosyncratic (i.e. $h_{i}$ ) haircut.The overall liquidity condition implied by this model writes as:

$$
A_{i}^{L}+\left(1-h-h_{i}\right) A_{i}^{C}+\frac{\left(1-h-h_{i}\right)}{(1-h)} A_{i}^{R R}+L_{i}^{N}-L_{i}^{R}-\lambda \mu_{i} L_{i}^{I B}-\varepsilon_{i}>0
$$

where $\varepsilon_{i}$ is the liquidity shock suffered by the bank, $L_{i}^{N}$ is the amount of new interbank borrowing bank $i$ can raise when a liquidity shock occurs, and $\mu_{i}$ is the share of bank $i$ 's neighbors that decide to withdrawn a fraction $\lambda$ of liquidity.

After making some simplifying assumption on the specification of some parameters of the model, the authors show how a tipping point condition can be analytically derived. In particular, by assuming that each bank is connected to exactly $z$ neighbors (both as lender and as borrower), idiosyncratic haircut shocks are set to zero (i.e. $h_{i}=\varepsilon_{i}=0$ ), banks have all the same balance sheet, full withdrawn is assumed in case of liquidity hoarding $(\lambda=1)$, and any unsecured interbank lending can be raised (i.e. $L_{i}^{N}$ ), then contagion will propagate if and only if:

$$
z<\frac{A^{I B}}{A^{L}+(1-h) A^{C}+A^{R R}-L^{R}} .
$$

Put it differently, provided that there is enough connectivity to transmit the shock (i.e. $z \geq 1$ ), the validity of the previous condition means that just one initial case of liquidity hoarding is sufficient to let the contagion process cascade to the entire financial system and hence cause a liquidity crises.

Using numerical simulations, Gai et al. (2011) also show how different network 
configurations, types of shocks and policy experiments can alter the probability of observing systemic liquidity crises. First, they consider a scenario where the interbank network is generated using an Erdôs-Rényi model (Erdôs and Rényi, 1960) and the liquidity shock originates by assuming that a single bank receives such a large adverse idiosyncratic haircut shock (i.e. $h_{i}=\varepsilon_{i}>>0$ ) that forces the bank to start hoarding liquidity. In such scenario, the results are in good accordance with the ones predicted by the analytical (simplified version) of the model: probability of contagion first increases and than decreases, is a non-monotonic way, when connectivity is varied and - whenever contagion breaks out - it spreads throughout the entire system. Second, they test what would happen when the aggregate haircut is raised (i.e. $h=h+\varepsilon$ ). In this case, the tipping-point threshold increases: i.e. a much greater level of connectivity ( $a k a$ level diversification of funding) will be needed to avoid contagion. Therefore, bank runs become more probable than in the first scenario. Third, the authors alter the topology of the interbank market, using a network model that generates a fat-tailed distribution of degrees to represent a more concentrated interbank market than the one analyzed in the previous two scenarios. The results are that: contagion becomes less probable and less severe when levels of connectivity are low but it can still occur at much higher levels of connectivity (although chances are rare). Fourth, when shocks are targeted to the most-connected bank, contagion is shown to realize more frequently, especially when the network is scale-free. In such cases, systemic liquidity risk is almost always a certain event. Lastly, the authors show that whenever market activity increases (i.e. the share of the interbank lending increases), also the likelihood of contagion increases. Furthermore, when the aggregate haircut is allowed to follow a cyclic behavior as it would happen during the evolution of a crisis, the system can suddenly become more vulnerable and more prone to collapse.

From a policy perspective, Gai et al. (2011) demonstrate how imposing targeted liquidity requirements is more effective than increasing them for the same amount for all the agents; despite the fact that tougher liquidity requirements make the system more stable all the same. Furthermore, they also show that setting timevarying requirements (i.e. counter-cyclical liquidity requirements) can offset the effects of having cyclic changes in aggregate haircuts. Lastly, they argue that a policy promoting transparency could help reduce systemic risk by reducing the strength of the withdraw that each bank execute when it is in need of liquidity (i.e. a policy that reduces the value of parameter $\lambda$, as defined before).

So far, we have considered only models that specifically include interbank lending as the main mechanism of contagion.Instead, Caccioli et al. (2014) show how phase 
transitions can appear also when only an indirect channel of contagion is present: i.e. price changes on common assets. In other words, the authors show how overlapping portfolios can be a main cause of financial contagion and systemic risk. They explain how leverage, market crowding, level of diversification, and market impact determines the stability (or lack of thereof) of the financial system.

In this case, the financial system is represented as a bipartite graph where there are $N$ nodes of type one, representing the banks; and $M$ nodes of type two, representing the investment assets. An investment from bank $i$ to asset $j$ is denoted with a link connecting node $i$ of the nodes of type one with node $a_{j}$ of the nodes of type two. The degree of bank $i$ can be interpreted as the level of diversification of the bank $\left(\mu_{u}\right)$. Instead, the degree of an asset $j$ corresponds to the number of banks that hold that asset in their portfolios. A crowding parameter $n$ is introduced to measure the level of portfolio overlapping and it is defined as the ratio of the number of banks over the number of assets present in the market. The larger the value of $n$, higher the level of portfolio overlapping between banks.

The assets side of the balance sheet of a bank comprises: fully liquid assets (i.e. cash, $C_{i}$ ) and the value of the assets portfolio $A_{i}^{t}$ :

$$
A_{i}^{t}=\sum_{j=1}^{M} Q_{i j} p_{j}^{t}
$$

where $t$ denotes the time period, $Q_{i j}$ is the amount of shares of asset $j$ held by bank $i$ (and this quantity does not vary over time) and $p_{j}^{t}$ is the price of asset $j$ at time $t$. Then, if we denote with $L_{i}$ the amount of total liabilities held by bank $i$ and with $E_{i}^{0}$ its capital, then a generic bank $i$ remains solvent if and only if:

$$
\sum_{j=1}^{M} Q_{i j} p_{j}^{t}+C_{i} \geq L_{i}
$$

or

$$
A_{i}^{0}-\sum_{j=1}^{M} Q_{i j} p_{j}^{t}+C_{i} \leq E_{i}^{0}
$$

We can also rewrite the solvency condition in terms of the initial leverage of bank $i$, where leverage is defined by $\lambda_{i}=A_{i}^{0} / E_{i}^{0}$ :

$$
\lambda_{i} \leq \frac{\sum_{j=1}^{M} Q_{i j} p_{j}^{t}}{E_{i}^{0}}+1 .
$$


In addition, the authors also assume that whenever a bank becomes insolvent, it liquidates all its portfolio. As a consequence, prices of the fire sold assets will drop. As a result, contagion will spread to all the banks that have investment strategies similar to the one of the failing bank. This occurs because portfolios are assumed to be marked-to-market.

In this model, probability of contagion is defined as the probability that a global cascade of failures occurs after an initial negative shock. A global cascade is defined as a cascade that affects a finite fraction of the banks present in the system once the system is large. That is, once we let $N, M \rightarrow \infty$ while keeping $\mu_{u}$ and $n=$ $N / M$ finite. From another point of view, this also means that the authors want to understand how likely it is to observe a large cascade of defaults in cases when the initial shock had an infinitesimal initial impact on the state of the system. Extent of contagion, instead, is defined as the average size of the cascade once one has occurred.

Using a generalization of the Galton-Watson process (Watson and Galton, 1875 , Mode, 1971), Caccioli et al. (2014) provide an analytical framework that can be used to compute the size of the default cascade after the bankruptcy of a bank. The failing bank is treated as the progenitor of the branching process, while the banks that fail at the next time period are the offsprings. Furthermore, as far as the paralellism with the generalized Galton-Walton process is concerned, banks with different properties are considered as individuals of different types. Using this analytical framework, the authors are able to provide a sufficient but not necessary condition for global cascades to occur. In particular, assuming that banks' portfolios and market impact function are known, a so-called stability matrix can be computed which can then be used to check whether or not - after an initial shock - contagion propagates.

In the following, we summarize their main conclusions. As far as phase transitions are concerned, similar to what was observed in Gai and Kapadia (2010); Gai et al. (2011), a contagion window exists. In particular, two different phase transitions $-\underline{\mu_{u}}$ and $\overline{\mu_{u}}$ - exist with respect to the level of connectivity in the bipartite graph (i.e. $\mu_{u}$, the level of portfolio diversification). Whenever the initial shock is a devaluation of one particular asset ${ }^{6}$ and $\mu_{u}$ is lower than $\mu_{u}$ or greater than $\overline{\mu_{u}}$, no global cascades can occur because for sufficiently low levels of $\mu_{u}$, there is not enough connectivity in the market to allow for the negative shock to propagate. On the contrary, for sufficiently high levels of $\mu_{u}$, the level of diversification is so high that the

\footnotetext{
${ }^{6}$ This type of shock mimics a situation in which the event that triggers contagion is the presence of a so-called toxic asset, i.e. an asset whose value is strongly devalued at time $t=0$.
} 
strength of the initial shock quickly dies out, without causing a systemic collapse. A robust-yet-fragile behavior is found for values of diversification very close (but lower) than $\overline{\mu_{u}}$ : i.e. global cascades are rare but when they do happen, their extent is as large as (almost) the entire financial system. In addition, the authors show that the position of the contagion window shits to the left whenever the crowding parameter $n$ is increase. As a consequence, contagion probability is a non-monotonic function of $n$ since - depending on the level of diversification of the system - a variation of $n$ can lead to either an increase or a decrease in the likelihood of a systemic crisis.

In terms of types of shocks, the authors also show that when a random default of a bank is imposed upon the system, instead of the devaluation of an asset, the underlying dynamics of contagion are not altered. That is, all the previous findings remain unchanged. The only observed difference is a change in the value of the probability of contagion. They also demonstrate that in financial systems where the leverage is kept low, systemic stability is guaranteed. Put it differently, there exists a critical value of $\lambda$ below which global cascades cannot occur and higher is the level of diversification of the system, higher this critical value would be. Lastly, in a simple extension of the model, Caccioli et al. (2014) also argue that allowing banks to liquidate assets before being found insolvent - for example by allowing them to keep their leverage constant after some assets have been devalued - only worsen the resilience of the financial system since it creates a positive feedback mechanism that exacerbate contagion.

So far, we have learnt that phase transitions may be strictly linked, in non trivial ways, to average properties of the whole network, i.e. average degree. This seems also to imply that understanding contagion effects on networks should require monitoring the detailed structure of the entire network and its evolution over time. Amini et al. (2012) challenge this idea. In particular, they observe how a phase transition occurs whenever the magnitude of the shock is above a certain threshold which is in turn determined by the connectivity structure of the financial system.

As in the other cases, the interbank market is modeled as a weighted directed graph where each node represents a bank and link weights are interbank assets and liabilities. Banks have stylized balance sheets that include interbank assets, interbank liabilities and other forms of assets and liabilities (e.g. deposits). The net worth of a bank, as given by its capital, represents the capacity of each bank to withstand a loss before becoming insolvent. The capital ratio is defined as the ratio between capital and interbank assets (not total assets). In this framework, the in-degree of a bank would correspond to the number of creditors and the out-degree to the number of debtors. Every directed link represents an exposure between two 
institutions. Furthermore, a link is called contagious if it represents an exposure that is larger than the capital of the lending bank.

They also introduce a resilience measure that is a function of the distributions of in- and out-degrees and on the proportion of contagious links in the network. When the resilience measure is positive, as long as the initial fraction of defaults is below a certain threshold, no cascades will occur. Instead, when such measure is negative, with high probability any node belonging to a connected set that represents a positive fraction of the financial system can trigger the collapse of the whole system. These results hold without assuming a specific probabilistic model for the degree sequence of the nodes or the balance sheet data of banks as long as some mild assumptions are satisfied. Put it differently, they show that positivity of the resilience measure is a necessary condition for avoiding the collapse of the entire financial system. Shocks are applied to banks' balance sheets by exogenously reducing their external assets by a certain fraction. Then, they study how the default of a given share of nodes affects the resilience and stability of the financial network. They show that there exists a threshold about the size of the negative shock above which the network becomes unstable and vulnerable to contagion. That is, there is a phase transition that indicates the maximal tolerance for stress of a network. Put it differently, if the resilience measure is positive, then as the initial fraction of defaults converges to zero, also the probability of having contagion does. However, if the resilience measure is positive, contagious links percolate and we can have global cascades for any arbitrarily small fraction of initial defaults. As a consequence, from a policy point of view, the resilience measure suggests that it is important to monitor only the subgraph of the contagious links. Therefore, it is crucial to monitor capital adequacy of institutions with respect to their largest exposures, i.e. the ones that can cause a bank to fail entirely. This also implies that there is no need to monitor the entire network.

\section{Homogeneity vs Heterogeneity}

In the foregoing sections, we have discussed a number of models that are mainly concerned with the structure of the financial network, but that make fairly simplifying assumptions on the characteristics of banks. However, intuition suggests that bank intrinsic characteristics may play a key role in determining the stability of the interbank market. In this section, we shall therefore analyze how bank heterogeneity, along different dimensions, influences the resilience and the stability of the financial system. 
A first dimension along which bank heterogeneity determines the level of systemic risk concerns their size. This issue is studied in Iori et al. (2006), who build a model where bank's primary purpose is to invest consumers' deposits. Resources invested will remain illiquid until the investments reach maturity and investment opportunities are stochastic and bank-specific. In the system there are $N_{t}$ banks at each time-step $t$. Each bank observes stochastic liquidity shocks that can cause them to be short in liquidity and for this reason banks form an interbank lending market. The linkages between banks are described by the binary undirected graph randomly generated from an Erdős-Rényi model (Erdős and Rényi, 1960) with parameters $\left(p, N_{t}\right)$ ( $p$ is the probability that a link exists). As a result of the random shocks to liquidity, at any $t$, each bank would be either in a borrowing state, i.e. it has a liquidity deficit, or in a lending state, i.e. it has a surplus of liquidity. Then, during the simulation, each borrowing bank will contact, at random, different neighboring lending banks in order to receive enough credit that will allow the bank to pay off its obligations, either towards other banks (i.e. interest rates from previous loans) or towards its depositors (i.e. interests on deposits). For each transaction, the amount exchanged between banks is equal to the minimum between demand and supply. Also, a borrowing bank does not receive the liquidity requested until it has lined up enough credit - possibly from many counter-parties - to ensure that it will not fail during the current period. The matching procedure iterates until no further trades are available. Then, banks left with negative holdings of liquidity or that fall short of their remaining debt obligations default. Defaulted institutions are removed from the system and their assets are distributed to depositors and creditors. As mentioned, banks can be either homogeneous or heterogeneous in their size. In the former case, they all have the same amount of deposits at the beginning of the simulations; while in the latter initial deposits are normally distributed. Fluctuations of deposits during the simulations are modeled in three different ways. In the first case, deposits vary proportionally to the square root of each bank's size (model $A)$; in the second case, deposits vary proportionally to banks mean size (model $B$ ); and in the third case, banks face identical deposits distributions but differ by a scale factor in their investment opportunities distributions (model $C$ ).

Simulations show that, in the homogeneous case, model $A$ and model $B$ give qualitatively similar results: increasing connectivity increase stability since more banks - ceteris paribus - survive when the density of the network is higher. Higher reserve requirements, instead, interact non-linearly with the risk of bank failures. Increasing reserves requirements, initially increase the number of failures but after a certain point the effects are reversed. That is, increasing reserves stabilizes banks 
at the individual level but also reduces the insurance that each institution provide to each other and the amount of resources shared will be reduced. However, when the threshold is set high enough, the individual stability effect completely dominates the second one and the interbank market freezes due to lack of disposable liquidity. At lower values of reserves, instead, the opposite holds. In terms of contagion, two properties are consistently observed (for a wide range of parameterizations): higher connectivity leads to a slowing down of the rate at which banks fail, i.e. "knock-out" effects from the failure of individual banks are not significant. In the heterogeneous case, increasing connectivity improves the stability of the system, while increasing heterogeneity makes the system more stable in model $A$ but not in model $B$ and $C$, where heterogeneity makes it more unstable. Once contagion occurs, an increase in connectivity leads to less failures at low levels but to more failures after a certain threshold. Therefore, connectivity stabilizes the system up to a certain point but whenever defaults start - higher interconnectedness may lead to default avalanches.

Amini et al. (2013) analyze instead the role of heterogeneity due to connectivity in the network. In other words, instead of looking at banks heterogeneity in terms of their sheer size, they focus on the number and size of the connections that banks have (i.e. node degree and exposure sequences are heterogeneous across nodes). As in the previous works, the model portrays $N$ banks and a directed weighted graph representing the financial system. Nodes represent banks, whereas edge weights describe exposures. Node in-degree denotes the number of debt obligations of that bank and node out-degree represents the number of credit obligations. Banks balance sheets are composed by interbank assets and liabilities, deposits, capital and other assets. Finally, capital ratio is defined as the ratio of bank's capital over interbank assets.

In their numerical simulations, Amini et al. (2013) analyze three cases: in model $A$, the network is scale free with heterogeneous weights (i.e. exposures).7 In model $B$, the network is still scale free but link weights are homogenous. In model $C$ an Erdős-Rényi graph (Erdős and Rényi, 1960) with homogeneous weights is employed. Across the three models, nodes have the same average degree. That is, the total number of links in the three networks is the same. This allows the authors to assess how results change when average connectivity is kept constant but the actual network topology changes along other dimensions. Scale-free networks are obtained using the random graph model introduced by Blanchard et al. (2003). In this model, for a given out-degree sequence, an arbitrary out-going edge is assigned to an end-node $i$ with probability proportional to $\left[n d_{\text {out }}(i)\right]^{\alpha}$, where $n d_{\text {out }}(i)$ denotes the out-degree

\footnotetext{
${ }^{7}$ More precisely, the distribution of link weights follows a Pareto distribution.
} 
for node $i$ and $\alpha>0$ is a constant parameter. As a consequence, there is a positive correlation between in- and out-degrees with out-degrees being Pareto distributed, and in-degrees being Poisson distributed.

The main result is that the most heterogeneity is introduced, the least the resilience of the network. Indeed, model $C$ is found to be the most resilient. Also, average connectivity turns out to be a too-simple statistics to explain network resilience. Knowing more detailed information regarding the topology of the network, e.g. the degree distribution or the distribution of link-weights, is essential to understand how contagion may evolve. Furthermore, when the network is scale free, there exists a minimal capital ratio such that, below a certain threshold, the number of defaults diverges. Additionally, given the initial default of a single node, the size of the default cascade increases with the in-degree of the initial defaulting node.

Banks heterogeneity in terms of degrees and assets is instead studied by Caccioli et al. (2012), who extend the Gai and Kapadia (2010) model. To explore the role of degree heterogeneity, they replace the usual Erdôs-Rényi random graph (Erdôs and Rényi, 1960) with a scale-free one wherein node in- and out-degrees are powerlaw distributed. The network is a directed weighted graph where, once again, edge weights represent exposures (i.e. interbank liabilities and assets). Simulations show that a scale-free topology reduces probability of contagion but does not impact its extent when the defaulting bank is chosen at random. However, scale-free networks are more fragile when a high-degree node is the target of an attack. Hence, probability of contagion is higher in the case of a targeted attack, even though extent of contagion remains unaffected. The robust-yet-fragile property of the financial system is therefore preserved.

As far as assets heterogeneity is concerned, Caccioli et al. (2012) study how contagion evolves when bank balance sheets are highly non-uniform, that is when the distribution of assets is power-law. The ratio of the total amount of interbank assets over total interbank liabilities is kept constant across nodes. As a consequence of this new configuration, banks are no longer uniformly exposed to the failure of one of their neighbors. Instead, diversification will be less effective in this scenario. When the network is modeled according to an Erdôs-Rényi random graph (Erdôs and Rényi, 1960) and assets are distributed according to a power-law distribution, the authors observe that the window of contagion gets wider as compared to the case when assets were uniformly distributed.

Combining the two forms of heterogeneity (over both degrees and assets), it is possible to investigate whether the systemic importance of an institution depends on whether it is too-big-to-fail or rather because it is too-connected-to-fail. Results 
indicate that two different regimes co-exist. When average connectivity is low, the probability of contagion due to the failure of the most connected bank is higher than that due to the failure of the biggest node. However, when connectivity is high, the opposite holds. Since real networks appear to be closer to the second scenario, it seems that having banks that are too-big-to-fail is indeed the issue. Additionally, as in the previous cases, the extent of contagion is not altered by assuming heterogeneous assets distributions instead of an uniform assets distribution. In terms of capital requirements, the authors also find that targeted policies that increase capital buffers for few, well-connected nodes are not an effective measure to reduce the probability of contagion when heterogeneity is only on the degree distribution of nodes. However, in presence of heterogeneity on balance-sheet sizes, a targeted policy that increases the capital buffers of biggest banks when average connectivity is high leads to a reduction of the contagion probability.

Caccioli et al. (2012) also analyze what happens when disassortative mixing is introduced. That is, when well connected banks tend to connect with nodes that have few connections, and viceversa. They found that - when an Erdôs-Rényi random graph (Erdôs and Rényi, 1960) is used - disassortativity reduces the probability of contagion. Instead, assortativity in node mixing increases the instability of the system. The underlying intuition is that, in a disassortative network, highly connected nodes act as a screen reducing the probability of failure of less-connected nodes, with whom they are linked. Instead, in an assortative network, poorly connected nodes would have been linked only among themselves and that would make them more prone to failure in case of the default of a neighbor.

A last source of heterogeneity that has been analyzed in the literature regards default probabilities. To explore this issue, Lenzu and Tedeschi (2012) analyze a case where link formation is endogenous and agents differ in their threshold probability of default: the higher the threshold probability, the higher bank expected profits. The model depicts a discrete-time system where there are $N$ banks that are interconnected through credit relationships. A bank balance sheet is composed of long term assets, short term debt and equity. Since no liquidity is immediately available in the market it must be exogenously generated. Therefore, liquidity surpluses are generated as positive shocks affecting individual banks, while liquidity needs are modeled as negative liquidity shocks. As a consequence, contagion may arise when a bank is hit by an exogenous negative shock to liquidity.

The authors study systemic risk when two random banks are shocked independently, one with a positive shock on liquidity and the other with a negative shock of the same magnitude. The banking network is analyzed as a flow network, where 
credit lines are seen as a way to let the liquidity flow from the node with a liquidity surplus to the one that has a shortage. Furthermore, specific constraints on the lending capacities between each pair of nodes are established. These constraints define the maximum liquidity flow allowed through existing links. Therefore, the flow network is a directed weighted graph where the weight of each edge specifies the liquidity capacity of the link. Transfers of liquidity happen through bilateral lending agreements entered by banks, where the probability that a lender borrows money to another bank depends on the creditworthiness of the borrower - as determined by its expected future profits. Therefore, link formation behaves according to a preferential attachment mechanism where safest and most profitable agents are able to secure more credit lines than weaker banks. Lending capacity, in this case, is defined as being the maximum amount of liquidity that a generic lender $i$ is willing to provide to a generic borrower $j$. The strength with which preferential attachment works depends on a herding parameter that determines the signal credibility of the agent: the higher the parameter, the higher the trust on the expectation about others' profits. For low values of the credibility parameter, the graph generated corresponds to a random graph with a Binomial (or Poisson) in-degree distribution, where the number of in-neighbors is the number of potential lenders a bank can rely on when additional liquidity is needed. As credibility increases, the graph evolves from an exponential graph, to a scale-free and finally, for high values of credibility, to a pseudo-star. In other words, when credibility is high, herding behavior emerges.

In terms of failures that occur because banks cannot raise any money, the authors find that even though random networks are characterized by a low credibility signal, they are more efficient in re-allocating liquidity - after the double liquidity shock from banks that have a surplus to the banks that have a shortage. Instead, as the network becomes scale-free with the increase in the credibility signal, banks become more prone to failure due to illiquidity. In particular, there would be just a small number of highly trusted agents, leaving all others with very few credit lines and hence being more exposed in case of negative liquidity shocks.

As far as defaults caused by contagion are concerned, instead, the authors observe that betweenness centrality $\square^{8}$ and graph diameter $\square^{9}$ describe pretty well the frequency of default for different levels of credibility. Betweenness decreases linearly with credibility and therefore also re-allocation efficiency decreases, since having more

\footnotetext{
${ }^{8}$ Betweenness centrality measures node centrality in a network. It is equal to the number of shortest paths from all nodes to all others, which pass through that node.

${ }^{9}$ The diameter of a graph is the longest shortest path (i.e., the longest graph geodesic) between any two nodes of the graph, where a geodesic between any two nodes is defined as the shortest path (i.e. the shortest number of edges) that must be traversed to go from a node to the other one.
} 
paths passing through the nodes means also that defaults of illiquid banks are less frequent. Defaults for insufficient flow, instead, depend mainly on the diameter of the network. The lower the diameter, the easier it is to transfer liquidity from nodes with surpluses to nodes with shortages. When credibility levels increase, the network becomes more fragmented and therefore the diameter increases making default cascades more likely. In terms of node median capacity, the authors observe that a sharp decrease in median capacity leads to higher instability. In a random network, different banks have roughly the same capacity, whereas when the in-degree distribution becomes power law, capacity is concentrated in fewer nodes. That is, there will be few very large nodes and many smaller nodes. This also means that only few nodes will be able to transfer liquidity. Hence, most of the nodes do not have access to many lenders and thus will fail for lack of liquidity. The average capacity, however, increases with credibility, suggesting a strong heterogeneity in participants' size. This heterogeneity leads the system to be more fragile since there exists a positive correlation between heterogeneity and the number of bankruptcies.

Lastly, Loepfe et al. (2013) show how heterogeneity in the size of the shocks, in the size of agents and in the level of connectivity can affect the stability of the financial system and how a macro-prudential approach to regulation can be used to control systemic risk. The model is described as follows: there exist $N$ risk-neutral financial firms (i.e. banks) and each agent invests a given amount of money on a risky project which gives a random return at the end of the time period. The financing of the project is obtained by issuing liabilities in the form of deposits or bonds that carry a deterministic interest rate. Then, a random shock determines the level of returns of the investments and therefore the ability of the banks to repay their debts. Diversification is made possible by allowing banks to enter risk-sharing agreements (i.e. cross-holding of assets). As a consequence, contagion is generated by the exposure to common assets: i.e. the failure of a given investment projects will produce losses not only on the investing agent but also on the agents that hold a share of the assets of the initial investor. The results of the model are following. From an analytical standpoint, the authors find that when the shocks are relatively small (i.e. the distribution of the shocks has thin tails), the optimal configuration favors the creation of a single connected component where the level of diversification is the highest; instead, when the distribution of shocks is fat tailed, the optimal configuration is one in which the level of segmentation (i.e. modularity) is the highest. In terms of degree heterogeneity, assortative mixing is preferred to disassortative mixing. In their numerical simulations, the authors use a modified version of the preferential attachment model to generate networks with given characteristics in 
terms of the level of modularity and degree heterogeneity. From a numerical standpoint, Loepfe et al. (2013) show that: the level of capital is the most important parameter in determining the stability of the financial system; when attacks are targeted to the too-big-to-fail banks, having high size heterogeneity is detrimental to the stability of the system; the same principle applies when the attacks target the too-connected-to-fail nodes and the heterogeneity regards the level of connectivity of the banks. Non-linearities exist in the way in which different parameters of the models interact. For example, the level of modularity is not important to determine the level of stability of the financial system when density is very high (all nodes are effectively connected together) or very low. Instead, when modularity is low (i.e. the system is not strongly divided into communities of highly connected banks ), the number of defaults increases more steeply when the level of connectivity of the network increases. The authors also explain how the transition from safe regimes to risky regimes can be very sharp in two specific cases. Whenever shocks are drawn from a fat tailed distribution, the optimal network configuration moves from a connected system to an isolated system to prevent the diffusion of contagion. Furthermore, whenever link density is low and modularity and size heterogeneity are high, a critical range exists where very small variations in the structure of the network (i.e. the addition or rewiring of few links) can have disproportionate effects in terms of systemic risk.

\section{Imperfect Information, Moral Hazard, Portfolio Optimization and Bank Runs}

As we have seen so far, network topology and node characteristics may interact in non-trivial ways to determine the stability and resilience of the financial system. However, the foregoing results strongly depend on two related assumptions. First, financial markets are characterized by perfect information. Second, no misbehavior on the side of banks is considered. Starting from this observation, a number of contributions have explored setups in which either information about the financial robustness of agents is imperfect or banks have an incentive to misbehave. Furthermore, a different stream of works also address how banks can internalize market uncertainty and counter-party risk and endogenously determine network topology by bilaterally bargaining lending conditions (volumes and prices), monitoring peers creditworthiness, and - more in general - by adopting portfolio optimization techniques to allocate their exposures.

As far as imperfect information is concerned Battiston et al. (2012a) develop a 
model where banks balance sheets are interlinked through an exposure matrix and imperfect information regards agents' financial robustness. Therefore, the financial system is represented as a directed weighted graph where edge weights represent interbank assets and liabilities which can be either short-term or long-term and $N$ nodes represent the financial institutions (i.e. banks). This determines two possible externality mechanisms occurring when a bank defaults. First, a default of a neighbor implies a reduction of the lender's equity. Second, since agents borrow also short-term and information is imperfect, bank runs may lead to fire-selling that will cause a further loss for the agent. The first mechanism is called external effect of the first type, while the second is dubbed external effect of the second type. On the asset side, banks have short-term (liquid) assets, long-term (illiquid) assets, interbank liabilities, bank reserves, and long-term assets such as mortgages or bonds which are not traded within the interbank network. On the liability side, we have short-term debts, long-term debts, interbank liabilities, deposits, and long-term bonds held by the households. The equity base (or net worth) will be determined as a difference between total assets and total liabilities, while the equity ratio of each bank is defined as the ratio of equity over long-term (network) assets and it is used as an indicator of financial robustness.

Imperfect information is caused by the fact that agents know which banks have defaulted but they do not know the exposures towards their counterparties and therefore - they cannot compute their level of robustness. In terms of external effects of the first type, the law of motion that models the equity ratio implies that financial robustness worsens when the number of defaulting counterparties of the bank increases. Additionally, banks are assumed to evenly share their exposures with their neighbors. Given this formulation, the main determinant of default cascades will be the fraction of defaulting counterparties, which will in turn depend on the probability of having $k_{f_{i}}$ defaults among $k_{i}$ partners. If defaults are not correlated and the portfolio is large, having several simultaneous defaults among counterparties will be quite rare. Default cascades are studied in a case where the graph is regular with degree $k$ and the initial distribution of robustness is assumed to be Gaussian.

Four possible scenarios might emerge. First, a fragile system might be prone to systemic default even if there are no exogenous shocks. That is, cascade size tends to one as the mean of the distribution of the equity ratios of banks (i.e. the average robustness of the financial system) decreases. Conversely, cascade size remains constant with degree $k$ when average robustness is low enough. Put it differently, the structure of the network and the level of diversification do not matter. Second, diversification does prevent systemic defaults, but only when the overall financial 
conditions are not "too bad". That is, when financial robustness is not very different across agents and the exogenous shocks are not large, increasing connectivity makes the system more resilient. Third, diversification may lead to an increased systemic risk for a specific range of values. That is, when initial robustness is heterogeneous and many agents are fragile, an increase in connectivity means that the momentum caused by an initial set of defaults will not be dampened and it will indeed trigger a systemic default when diversification is high. Fourth, when the system is already fragile, diversification has no effect relatively to the exogenous shocks. That is, systemic default will occur regardless of the level of connectivity whenever agents are fairly homogeneous and average robustness is low.

In terms of external effects of the second type, the authors analyze the case when imperfect information leads to bank runs, i.e. short-term investors do not roll over their debt causing a liquidity problem to the banks. Bank $i$ may be illiquid even if it is still solvent, i.e. even if net worth remains positive. Then, $i$ will need to sell part of its long-term assets, such as securitized mortgages, to cover the value of liabilities to be repaid. Given imperfect information, the authors assume that there is a bank run of all creditors whenever the number of defaults is larger than a certain threshold that increases with the financial robustness of agent $i$. Therefore, by adding the external effects of the second type, a new law of motion for financial robustness will be obtained, where also the role played by fire-sells caused by bank runs is taken into account. When also the external effects of the second type are added, default cascades scenarios change as follows. First, diversification prevents systemic defaults whenever bank runs and large exogenous shocks are absent. In particular, as long as average robustness is positive and that the number of agents is large, there always exists a level of diversification that makes systemic defaults to disappear. Second, when bank runs are present, diversification has an ambiguous effect on systemic risk. The cascade size is first decreasing in $k$ but - after a certain threshold - it increases with diversification. Third, as found also before, when the system is already fragile, diversification has no effect relatively to the exogenous shocks. Additionally, when partial asset recovery is admitted, the system becomes more robust when diversification is small. However, when diversification is large, then there are no differences with respect to the case when there is no asset recovery.

We now turn to analyze models where banks have an incentive to misbehave. Brusco and Castiglionesi (2007) study how the structure of the interbank market influences financial contagion in the presence of both liquidity shocks and moral hazard. In particular, they show that contagion is a rare event since it is optimal to create financial linkages across regions and invest in the long-term asset only if the 
probability of bankruptcy is very low. The authors analyze first a model where only two banks and two regions are present and then a model with multiple regions (i.e. banks), studying what happens in network structures à la Allen and Gale (2000). That is, the networks are directed weighted graphs where all edges have the same weights and links represent cross-holdings of deposits between different regions.

In the basic model, there are three dates $(t \in\{0,1,2\})$, one divisible good (i.e. money), two banks, two regions and three types of assets: (i) a illiquid safe asset; (ii) a gambling illiquid asset; and (iii) a liquid shortasset. The latter takes one unit of the good at date $t$ and stores it until $t+1$, keeping the same value. The safe and gambling assets, instead, generate a profit at period $t+1$. The gambling asset produces higher returns (but only in probability), whereas the returns from the safe asset are certain. Furthermore, the opportunity to invest in the gambling asset is a random variable and - when the returns are positive - a fraction of the profits is not observable by the depositors and it is appropriated entirely by the banks owners. This last feature of the model is what creates the moral hazard problem. Each region contains a continuum of ex-ante identical consumers (depositors) which are - once again characterized by Diamond-Dybvig's preferences (Diamond and Dybvig, 1983). This generates liquidity shocks in the regions. Additionally, there is a second class of agents, called investors, which are risk-neutral and are endowed with some units of good at date $t=0$. Investors can either consume their endowment or buy shares of banks which entitle them to receive dividends. In terms of contracts offered, banks can make contingent contracts, specifying the fraction of each dollar of deposit to be invested in the liquid short-term asset and illiquid long-term asset. However, no control can be enforced on whether the bank is investing in the safe or in the gambling asset. Also, banks respond just with limited liability. The authors show that, given bank's capital and given a contractual obligation of a certain amount of units of good to be invested in the long-term asset, the bank will invest in the safe asset only if the capital of the bank exceeds a given threshold. Therefore, depositors will invest in the long-term asset knowing which is the minimum level of bank capitalization necessary to avoid the moral hazard problem.

As far as liquidity shocks are concerned, we have that the two regions are negatively correlated in terms of liquidity needs. Therefore, banks find it useful to exchange deposits as a coinsurance instrument against regional liquidity shocks since the exchange eliminates aggregate uncertainty and allows the financial system to achieve the first-best equilibrium even when moral hazard behaviors are possible, provided that there is a sufficient amount of capital available. Instead, when the capital available is scarce, there are still parameters configurations where the opti- 
mal contracts for depositors will prevent moral hazard only in autarky, but not when financial markets are opened. The reason being that the possibility of coinsurance makes the investment in the long-term asset very attractive, making the depositors willing to accept the risk of their investments being misused by diverting money from the safe long-term asset to the gambling long-term asset. Also, the expected utility generated by the optimal contract will be a decreasing function of the probability of observing the gambling asset and it will converge to the first-best solution when such probability goes to zero (i.e. when there is no opportunity to invest in the gambling asset). Thus, if financial instability is accepted as a consequence of the opening of the interbank market, it must be the case that instability is a rare event.

The authors consider also scenarios where there are multiple regions and still one representative bank per region. They observe that the results obtained by Allen and Gale (2000) are reversed. That is, a more connected interbank deposit market increases the number of regions hit by bankruptcies as compared to the case where an incompletely connected market is considered. Contrary to Allen and Gale, here bankruptcies are caused by the moral hazard problem - i.e. banks investing in the gambling asset - not by an aggregate liquidity shock that is higher than what the aggregate resources of the financial system could bear. Furthermore, in such a case, no contagion would actually occur given the premises of Brusco and Castiglionesi's model, since contracts can be made contingent on aggregate liquidity shocks. The only non-contractable variable is the return on the gambling asset, which is the only source of contagion and financial instability.

The role of bank misbehavior is also analyzed in Castiglionesi and Navarro (2008), where now returns from investments - unlike in Brusco and Castiglionesi (2007) - also depend on the network structure of the interbank market, which is represented as an undirected binary graph. The setup still envisages three agents: consumers, banks and investors (i.e. banks' shareholders). There are three dates $(t \in\{0,1,2\})$, one divisible good (i.e. money) and $N$ regions. As usual, each region hosts one representative bank and a continuum of risk-averse consumers, which are endowed with one unit of good at $t=0$. Consumers, however, will consume only at $t=2$ and they have to deposit their endowment in the representative bank of their region until that date. Each bank receives a random endowment of dollars, which represents the bank's capital and it is owned by the investors. An interbank market exists and therefore banks can make transfers across regions. As a consequence, the total amount of capital for bank $i$ would be the sum of the endowment and of the interbank transfers. The sequence of events is the following: at $t=0$ banks receive 
their capital and choose the financial network; at $t=1$ banks' transfers are made and investments are chosen; and at $t=2$ cash flows are realized and depositors are paid. In terms of investments, banks can choose between two different long-term assets: a safe asset and a gambling asset.

As mentioned, unlike in Brusco and Castiglionesi (2007), here returns from investments depend on the network structure of the interbank market. More precisely, return to bank $i$ for each unit invested (regardless of the asset chose) is equal to $f\left(k_{i}\right) R$, where $k_{i}$ is the number of neighbors of $i$ and $f($.$) is function such that$ $f^{\prime}>0, f^{\prime \prime}<0, f(0)=1$ and $f(N-1)=\rho>1$. Therefore, the same amount invested in autarky (i.e. $k_{i}=0$ ) will yield lower returns with respect to the same investment made in an open interbank market (when $k_{i}>0$ ).

However, a trade-off exists. Connectivity is beneficial in terms of returns from investments, but has a negative effect on the actual probability that the project chosen by a given bank succeeds: whenever a bank fails, also all its neighbors will fail. For example, if we have a fully connected network with $N-1$ banks investing in the safe project and only one bank investing in the gambling project, the probability of success for each bank will be only equal to the probability of observing returns from the gambling asset. Instead, if autarky would have been chosen, $N-1$ banks would have been successful with probability one, while only one bank - the one investing in the gambling project - would have been successful with a probability equal to the likelihood of realizing returns from the gambling asset. This implies that the authors assume a very strong form of fragility within the system. Similarly to Brusco and Castiglionesi (2007), the authors show that banks have an incentive to invest in the gambling asset whenever they are under-capitalized. In particular, banks will invest in the safe asset only if bank capital is greater than a given threshold. This cut-off value is decreasing in the number of neighbors of a generic bank $i$, increasing in the number of gambling neighbors and increasing in the probability of success of the gambling asset. In this setting, the authors show that the decision of joining a (possibly) fragile financial networks can be justified (i.e. optimizing) even when the decision is made after that the endowments are realized, not only when there is still uncertainty about them. Therefore, uncertainty on endowments is not a necessary condition to form a fragile financial network, unlike what happened in Leitner (2005).

The model allows one to draw sharp conclusions in terms of optimal network configurations. For example, in the social planner case, a core-periphery structure emerges as the constrained first-best (CFB) solution to the problem. In particular, we have that the core is composed by the banks that are investing in the safe asset 
which will be all connected to one another. Instead, in the periphery, we will have "gambling" banks that can eventually be connected to some core banks and some peripheral banks, depending on the value of the parameters. That is, the higher the probability of success of the gambling asset, the more connected the periphery will be, since the risk of bankruptcy will be sufficiently low that the advantages coming from portfolio diversification (i.e. $f(k)$ ) will outweigh the risk of collapse. When, instead, the decision process is decentralized, we observe that core-periphery structures are still achieved (when no bank transfers are assumed), even though they may not be exactly equal to the optimal configurations and - in general - the investment profile will not be efficient. However, when the probability of success of the gambling asset is high enough, the decentralized solutions are very close to the social planner solutions. Instead, when the probability of success if low, inefficient structures arise in the decentralized case.

In the last three contributions of this section, we study how banks can internalize market uncertainty and counter-party risk and endogenously determine network topology by bilaterally bargaining lending conditions (volumes and prices), monitoring peers creditworthiness, and - more in general - by adopting portfolio optimization techniques to allocate their exposures.

Bluhm et al. (2014) develop a dynamic network model where $N$ heterogeneous banks endogenously determine their interbank lending/borrowing relationships. The balance sheet of each bank consists of: on the asset side, liquid assets (i.e. cash), interbank lending, and illiquid assets (e.g. bonds or collateralized debt obligations); while, on the liability side, we have deposits, interbank borrowing, and equity. Banks are heterogeneous in terms of initial equity endowments and returns on illiquid asset investments and it is this heterogeneity that determines their different portfolio allocations and their lending/borrowing behavior.

Each agent maximizes its expected profits and determines its optimal level of investments, lending, and borrowing while taking into account the level of prices for illiquid assets, the risk-free interest rate on the interbank market, and its own bankspecific returns on illiquid assets. Such maximization process is subject to a set of regulatory constraints on liquidity and capital. In particular, a given percentage of the bank's deposits has to be held in the form of liquid assets (i.e. cash) and the level of equity must be high enough that the risk-weighted capital ratio of the bank is equal or higher than a minimum value set by the policy maker plus a bank-specific level of capital buffer. As a consequence, banks will adjust their interbank exposures and/or their level of investment on illiquid assets to comply with market regulations during contagion events. The higher the risk-weights on interbank lending and 
illiquid assets are, the larger the re-adjustments after a negative shock (e.g. the failure of a counter-party).

In this contribution, two processes are pivotal in influencing the topology of the interbank market and the allocation of investments of banks: the equilibrium dynamics in the interbank market and in the market of illiquid assets. In the former, equilibrium interest rates are determined via a discrete tâtonnment process which finds the market-clearing rates that match the aggregate supply and demand of funds. In the latter, the equilibrium is found via a continuous tâtonnment process which finds the market-clearing price of illiquid assets such that total excess demand equal supply. In the interbank market, an efficient allocation of funds is found by determining not only equilibrium interest rates, but also bank-specific lending/borrowing amounts, risk-premia and equilibrium probabilities of default given the topological structure of the interbank market which is identified by using a closest-matchingpartner criteria. That is, a pair of banks will form a lending-borrowing relationship provided that the difference between their respective supply and demand for funds is minimal compared to the other possible pair candidates.

Contagion can be transmitted via a direct channel (i.e. a bank suffer a counterparty loss) or via an indirect channel (i.e. fall in market prices). Furthermore, banks can be forced to fire-sale parts of their illiquid assets and/or to re-adjust their exposures on the interbank market to meet the regulatory requirements. Bluhm et al. (2014) suggest the to use the so-called Shapley value (Shapley, 1952) to measure how much - on average - each bank (marginally) contributes to systemic risk, where the latter is computed as the ratio of the assets held by all defaulting banks over the total of the initial assets present in the financial system.

The initial negative shock to the system takes the form of a loss in banks' illiquid asset holdings. The analysis carried out by the authors evaluate the impact on systemic risk of changes to the capital and liquidity requirements imposed to the banking system, and to assets' risk-weights used in the computation of the riskweighted capital ratio. Furthermore, they also study the impact of policies that introduce taxes on interbank lending/borrowing and on investments on illiquid assets (i.e. the so-called risk charges). Lastly, they test what happens with the introduction of a central bank that intervenes in the interbank market to stabilize the equilibrium interest rates by dynamically adjusting the aggregate level of supply or demand of liquidity in the system. In this context, the central bank is assumed to have access to unlimited funds and it cannot default. In the numerical simulations, the number of banks is fixed to $N=15$.

In the following, we report the main results obtained. In equilibrium, banks 
with relatively higher returns on illiquid assets are also the ones which will have the highest level of leverage in the interbank market. Indeed, banks with low returns to illiquid assets will prefer to lend more funds and hence substitute investments on illiquid assets with interest rates from lent funds. Furthermore, the most leveraged banks are also the ones that are found to contribute the most to systemic risk in cases when an attack is targeted to them.

The effects of an increase in the liquidity ratio constraint are: the interbank market becomes more concentrated; banks are less leveraged; and the investments on illiquid assets are reduced. Overall, this leads to a reduction in the extent and probability of contagion since having less leveraged banks reduces systemic risk and less investments on illiquid assets reduce the strength of contagion via changes in asset prices. Despite the fact that we still observe a reduction on leverage, when the minimum required capital ratio is increased the market becomes less concentrated. This happen because the incentive to reduce interbank transactions will also reduce the distance between the optimal level of investments chosen by the different institutions. Therefore, the heterogeneity that exists at the level of returns on illiquid assets will play less of a role in determining the relative size of lending of the different agents.

In this model, raising the minimum requirement on capital will make the interbank market more sparse and reduce systemic risk. Instead, when connectivity is increased, the authors find that the contribution to systemic risk always increases. The introduction of taxes reduces both the incentives to borrow and invest. As a result also systemic risk decreases since the interbank market dries out and banks' balance sheets are less vulnerable to changes to asset prices. The presence of a central bank reduces the strength of the interbank linkages and therefore the (marginal) contribution to systemic risk of each bank becomes much smaller.

In a similar fashion to what has been proposed in Bluhm et al. (2014), Halaj and Kok Sorensen (2014) develop a model where the topology of the interbank market is determined by banks optimizing behavior. In particular, financial institutions optimize their asset and funding structure while taking into account - among other things - their expected income, interest rates volatility, counter-parties' probability of default and regulatory constraints. In this framework, banks are once again heterogeneous in terms of their balance sheet size, initial capital endowment, profitability of illiquid assets, and probability of default. However, banks engage in a bargaining game to determine the final matching of supply and demand of funds in the interbank market.

In this framework, three main assumptions are deemed to hold: each bank knows 
its own aggregate level of lending and borrowing and the ones of the other agents; banks optimize also the structure of their interbank lending agreements; and diversify funding sources to minimize refinancing (rollover) risk. Contrary to the previous work, the authors assume that banks are risk-averse, not risk-neutral. Indeed, during their optimization process, they have to obey to internal risk limits based on the so-called Credit Valuation Adjustment (CVA) concept which takes into account of the market perception of the credit risk associated to interbank exposures (see Deloitte and Partners (2013)).

Formally, the model is defined as follows. There exists $N$ banks. Each bank $i$ aims to invest a given amount of interbank assets and to collect a given amount units of interbank liabilities. Interest rates paid on interbank deposits are endogenous and depend on some reference interest rate, on the credit risk of the counter-party, on market's liquidity, on bank's $i$ access to the market, and on the value of the loss given default (exogenously fixed). From a network formation standpoint, banks are assumed to trade more likely with trade partners they have already met in the past. This also serves to proxy the effects of geographical proximity: i.e. banks in the same market trade more frequently among themselves with respect to what they do with foreign partners.

Links creation develops using a sequential algorithm consisting of four different steps that are repeated until full allocation of interbank assets is achieved. First, banks determine the optimal level and structure of interbank assets maximizing their risk-adjusted returns subject to regulatory large-exposure-limits (i.e. each individual exposure should not exceed a given fraction of the total regulatory capital of the bank). Second, funding banks either accept or decline the allocation proposed at step one by borrowing banks. Then, after minimizing their own funding risk (i.e. the risk that bank $j$ will not roll-over credit), each bank $i$ determines whether or not to accept the funding offer made by bank $j$. Third, the bargaining game occurs: i.e. agents engage in pair-wise bargaining sessions in which they settle on acceptable deviations from their desired interbank allocations. In the fourth step, to overcome the fact that the individual optimizations and the bargaining game might not lead to a full allocation of the interbank assets, banks suffering from funding deficiency adjust their offered interest rates.

Halaj and Kok Sorensen (2014) calibrate their model on a sample of eighty European banks for which the authors have information regarding their balance sheet structures. The results they obtain are the following. The endogenous network generated by the model does not show a clear core-periphery structure. As the authors point out, this is probably due to the fact that only global, internationally active 
banks are included in the sample. From a policy standpoint, the authors show how different regulations may alter the structure and the stability of the endogenously generated interbank market. They demonstrate that adding a CVA-based capital surcharge does not substantially change the topology of the network, other than for the weaker banks that are now less diversified. Similarly, raising the large exposure limits does not cause any major change in the dynamics of the model. However, once the limits are lowered (and hence the constraint is made more binding), banks are shown to reduce the size of their individual interbank exposures and to increase the number of counter-parties they deal with.

Lastly, they show that when an adverse economic scenario is imposed upon the system, the model will endogenously lead to a change in the characteristics of the interbank networks: when compared to a baseline model, some nodes become more interconnected even though overall connectivity was higher in the former case. In addition, under the adverse scenario, enforcing more stringent large exposure limits tend to lower the risk of contagion, especially for the banks that the market perceives as being particularly healthy. Instead, raising CVA-based charges will still benefit more the soundest banks, even though the effects on systemic risk are not as clear-cut as they were in the previous case.

In a more recent contribution, Blasques et al. (2015) develop a structural model of network formation where banks can engage in costly peer monitoring to deal with the presence of asymmetric information about the level of risk associated with their counter-parties. Within this framework, the topology of the interbank network dynamically adjust to the liquidity conditions of the interbank market.

The model is defined as follows. The interbank market consists of $N$ banks with a time-varying number of weighted directed links between them where each directed edge represents a loan granted from a bank to another bank and its weight represent the amount of the loan and the applied interest rate. In each time period, banks are subject to exogenous liquidity shocks (i.e. liquidity demands from depositors). Banks' objective is to maximize their profits while selecting their counter-parties and deciding how many resources to invest in peer-monitoring efforts. Liquidity shocks are modeled as independently and normally distributed random variables with a bank-specific mean and variance. Furthermore, positive correlation exists and larger banks are assumed to have a distribution of liquidity shocks with a larger variance. Instead, in distribution, there is no true heterogeneity in banks' probabilities of default.

Asymmetric information causes banks to judge their peers by their perceived probability of default. The evolution of the perception error crucially depends on 
two different sources of knowledge: past trading history and (costly) peer-monitoring efforts. In the interbank market, agents negotiate interest rates - bilaterally - according to a generalized Nash bargaining process (see Afonso and Lagos (2014) for details). The bilateral equilibrium interest rate is a function of the true default thresholds of the counter-parties and of their true and perceived financial distress variances. Therefore, banks will pay a risk-premium based not only on their true probability of default but rather on their perceived probability of default.

To mitigate the effects of asymmetric information, banks can engage in costly peer-monitoring to reduce the variance of the perception error at future time periods. The probability of an encounter between two financial institutions depends on the level of search efforts put up by the bank. The optimal level of peer-monitoring and search efforts each bank decides to undertake towards a specific bank depends on the surplus bank $i$ expects to obtain from bank $j$. Put it differently, adaptive expectations of bank $i$ about the bilateral credit availability and conditions provided by bank $j$ determine the optimal level of monitoring and search efforts.

The time structure of the model is defined as follows. First, at the beginning of each time step $t$, banks set their optimal level of monitoring and search efforts, and they observe a realization of the liquidity shocks. Then, links between banks are created, bargaining occurs and the variance of the perception error is updated. Lastly, at the end of each period, banks revise their expectations.

To analyze the insights obtained using this framework, Blasques et al. (2015) calibrate their model using the indirect inference approach (as explained in Gourieroux et al. (1993)) to loan level data from the Dutch overnight interbank lending market. The main findings of the model are the following. First, peer-monitoring, search frictions and asymmetric information on counter-party risk turn all out to be significant variables that are necessary to match certain characteristics of the interbank market such as high sparsity, low reciprocity, skewed degree distribution, and the core-periphery structure of the network. Indeed, the model is able to reproduce the tiered network structure that is present in the data where core banks tend to show a structural liquidity deficit and high variance in their observed liquidity shocks; while, peripheral banks show funding surpluses and low variance. Second, the core-periphery structure appears to be stable across time since banks tend to form long lasting lending-borrowing relationships. As a consequence, counter-party uncertainty tends to be reduced in those linkages which are also characterized by lower interest rates.

This feature of the model is found to be directly linked to the presence of the so-called multiplier effect from peer-monitoring. That is, after observing an initial 
liquidity shocks that increases the expected profitability of a loan, banks will respond increasing their monitoring and search efforts. As a consequence, more loans will be granted and at a lower interest rate. This will boost the incentive that banks have in further increasing monitoring and search efforts, creating a positive feedback which will generate the multiplier effect. Third, when - in the middle of a simulation - a large shock to the perception error variance is imposed, the sudden change in counter-party uncertainty can dry up the interbank lending activity for a prolonged period of time.

This happens because - suddenly - active trade partners observe a deterioration of the risk assessments they made on their usual counter-parties. This drives interest rates spreads to explode and also increases the incentive for banks to resort to the outside option, i.e. lending from/to the central bank. Furthermore, the worsening of banks' expectations also decreases investments in peer-monitoring and search efforts, therefore preventing a fast recovery of interbank lending. The lending network not only becomes less connected but also more concentrated after the shock.

Lastly, the authors show that when the central bank increases the width of the so-called discount window (i.e. the difference between the borrowing rate and the lending rate), the positive effects on interbank lending are indirectly multiplied by the fact that an intensified interbank trading pushes up also banksâĂŹ monitoring and search efforts, which - as we observed earlier - further improves the conditions of credit and the availability of market lending. However, the topology of the network becomes less stable since there is an higher probability of observing a match between two previously unknown partners. This also means that higher level of bank-to-bank uncertainty are going to be observed and - as a consequence - both the interest spread and the cross-sectional variation of spreads increases.

\section{Financial robustness, asset price contagion, and market regulations}

In addition to the determinants of systemic risk discussed so far, financial-system stability may be also influenced by the actual portfolio composition of banks. Indeed, the amount of capital and liquidity held by the banks, as well as the effects that endogenous changes in asset prices have on stability, all contribute to determine how negative shocks propagate through the interbank network. This issue is take up in a series of articles, which we briefly review in this section.

A first set of papers (e.g. Cifuentes et al., 2005, Nier et al., 2007; May and Arinaminpathy, 2010, Arinaminpathy et al., 2012) show how asset price changes, 
liquidity and capital requirements interact with connectivity in determining the resilience of the financial system.

For example, Cifuentes et al. (2005) study how capital requirements on banks can cause perverse effects when portfolios valuations are marked-to-market, mainly because financial institutions do not internalize the externalities entailed in their network relationships. In this setting, they demonstrate that systemic resilience and connectivity are non-linearly related, as it was shown by Allen and Gale (2000). However, more interconnected systems may be riskier than less connected ones under particular circumstances.

The authors consider $N$ interlinked financial institutions (i.e. banks) which are connected through an exposure matrix. Hence, we deal here with a directed weighted graph where linkages represent interbank assets and liabilities. Bank liabilities are marked-to-market and banks are assumed to have limited liability (equity cannot be negative). Also, there is the priority of debt over equity, implying that equity value is positive only if the notional obligations and payments of a bank coincide. Banks are required to have a minimum level of capital ratio, i.e. the ratio of bank's equity value to the marked-to-market value of its assets must be above a pre-specified threshold ratio $r^{*}$. When banks do not satisfy this requirement, they can sell assets for cash to reduce the size of their balance sheet and hence reduce the denominator, making the capital-asset ratio larger. In addition, it is assumed that banks cannot short sell the assets and that they can sell their illiquid assets only when all their liquid assets have already been sold. Demand for the illiquid assets is downward sloping. In order to compute the equilibrium, the authors use an iterative algorithm that determines at each round the set of banks that are oversized or insolvent and then computes the quantity of the illiquid asset that needs to be sold. Given this quantity, the equilibrium price is computed. Then, all banks re-evaluate their portfolios according to the marked-to-market requirements and the algorithm checks whether all banks are solvent under the new price. If that is the case, the process stops. Otherwise, the procedure is re-iterated until an equilibrium is found where all banks are solvent.

Notice that the actual portfolio composition of banks has a direct effect on banks' intrinsic creditworthiness, resilience to shocks and susceptibility to contagion. This implies that banks with significant holdings of liquid assets are less exposed to fluctuations of the price of the illiquid asset, face lower credit risk and create less externalities on the system when they need to settle their liabilities through selling. This happens because they will be selling more of the liquid asset, which has a fixed price, than of the illiquid asset. This generates less price fluctuations. However, banks do not internalize the positive externalities they have on the system when 
they hold more liquidity, therefore privately determined liquidity is sub-optimal. Liquidity and capital requirements have several effects on systemic resilience. In particular, liquidity requirements may be more effective than capital buffers in forestalling systemic effects, with liquidity and system connectivity that are substitutes for systemic stability for a wide range of parameter values. Furthermore, high liquidity requirements reduce the impact of contagion via the asset-price channel.

Mixed results are obtained as far as system connectivity is concerned. In particular, more connected systems may lead to higher resilience or higher systemic risk depending on the strength of contagion that occurs through the asset prices channel. That is, without this additional channel, increased connectivity is always beneficial, since it reduces the impact of a single default. When prices are endogenously changed, more connections may imply having more actors selling units of the illiquid asset to recover from their losses - especially when liquidity requirements are low - and therefore this may lead to an increased price impact. However, the asset price channel of contagion may disappear entirely when the number of interlinkages is high enough to allow banks to stand the losses only by selling liquid assets. Therefore, the effects of connectivity on systemic risk are non-linear.

The impact of portfolio composition on systemic risk is further analyzed by Nier et al. (2007), who employ a simulation model to analyze how the ability of the interbank network to absorb negative shocks is related to: (i) banks' capitalization; (ii) size of exposures; (iii) degree of connectivity; and (iiii) degree of concentration in the banking sector.

In Nier et al. (2007) the interbank system is modeled as a network where the $N$ nodes are banks and links represent directional lending relationships between two nodes (i.e. a directed weighted graph). The network structure is randomized using an Erdős-Rényi random graph (Erdôs and Rényi, 1960). For any realization of the network, individual balance sheets for each bank $i$ are randomly populated with external assets, interbank assets, bank equity, consumers deposits and interbank borrowings. To study systemic risk, the external assets of a given bank are hit by a negative idiosyncratic shock with size $s_{i}$, which wipes out a certain percentage of the external assets' value. The authors assume priority of (insured) customer deposits over banks deposits, which in turn have a priority over equity. A bank defaults whenever the size of the shock is greater than bank's equity. Losses are evenly distributed among creditors and depositors (provided the priority rules outlined before). Therefore, contagion may occur when the shock is not fully absorbed by the first bank being hit, and it transmits through the interbank network to bank $i$ 's creditors. In addition to this basic setting, two extensions of the initial model are 
analyzed. In the first one, liquidity risk is incorporated in the analysis. An inverse demand function for banking assets is assumed such that when a shock hits a bank, the price of external assets will decline with fire-sales and the total loss suffered will be magnified. In the second extension, a tiered network structure is assumed. In other words, the $N$ banks are split in two groups. First-tier banks are tightly connected nodes, which have a high probability of being connected among them, and a smaller likelihood of being connected with banks in the second group. The latter banks, which form the periphery, are mainly connected to first-tier nodes.

One of the main results of the model is that lower levels of equity increase in a non-linear way the number of contagious defaults, i.e. for high levels of equity the system is immune to contagion, while when the equity falls below a given threshold there is a sharp increase in the risk of a systemic breakdown. Furthermore, one can show that the bigger the size of interbank liabilities, the higher is the risk of "knock-out" defaults. As it happens in other models of systemic risk, contagion is a non-monotonic function of the degree of connectivity. Indeed, for low levels of connectivity, its increase enhances the chances of contagious defaults, while for high levels of connectivity, a further increase reduces the probability of a systemic breakdown. However, connectedness and the level of capitalization interact, i.e. for less-capitalized systems higher connectivity leads to higher contagion, while for well-capitalized systems the opposite holds. Moreover, higher concentration of the banking system tends to make the interbank network more vulnerable. Liquidity has a similar effect: when liquidity effects are introduced, systemic risk increases. Finally, as far as network structure is concerned, tiered-structures are not necessarily more prone to systemic risk than non-tiered banking systems.

May and Arinaminpathy (2010) develop a simple model which derives from the ones commonly used to study ecology that also includes - as a propagation mechanism - changes in asset prices. The model comprises $N$ banks which are characterized by a simplified balance sheet structure, as it was previously described in Nier et al. (2007) and in Gai and Kapadia (2010). Interbank linkages are randomly generated from an Erdôs-Rényi model (Erdôs and Rényi, 1960) and a mean-field approximation is used to study the possible knock-out effects of an initial failure. The system is treated as if it was completely homogeneous: i.e. banks have all the same size, the same level of connectivity and the same balance sheet structure. This simplification allows the authors to fully characterize the system from an analytical standpoint, using few parameters. The main findings of this work are the following. First, the negative shocks caused by a bank defaulting on its interbank loans tend to dissipate as the contagion unfolds. In other words, diversification dampens the 
effects of an initial default and higher the level of connectivity, more rapidly the shock attenuates. However, the opposite finding emerges when looking at liquidity shocks. That is, when asset prices (of possibly different types of assets) adjust as a result of fire-sales, the negative effects are amplified as more financial institutions fail since a positive feedback effect kicks in. Furthermore, the shocks to asset prices are felt by the whole financial system. Second, systemic risk is maximized whenever the level of interbank activity and external assets roughly balance. This also means that when banks operate both as investment banks and as retail banks the risk of a systemic collapse is the highest. Third, robustness is the highest when the level of capital is high. Lastly, the more homogeneous is the system - in particular when considering the proportion of different asset categories held by banks - the more fragile it is.

In a second contribution, May and Arinaminpathy add to their study the analysis of the role played by bank sizes in determining the stability of the financial system. In particular, in Arinaminpathy et al. (2012), the authors introduce a model where banks can be of two types, large and small, and interbank liabilities have two maturities, short-term and long-term loans. Short-term loans are the only ones that can be withdrawn by a bank within the same time interval; however, long-term loans can be transformed in short-term loans in one unit of time. Banks are not only interconnected by direct exposures, but - as in the previous contribution - they can have a shared exposure to the same category of external assets. Lastly, large banks are allowed to be both more diversified and more connected. Short-term loans can be recalled by banks because of the deterioration of the health of the lending bank (i.e. precautionary motive) or of its counterparties (i.e. counterparty concerns), because the market confidence is low, or because the liquidity is needed to meet financial obligations. Therefore, liquidity hoarding is endogenous and varies during each market simulation. Default cascades are simulated by failing a large bank, wiping out one of its external assets categories (chosen at random). What emerges from this work is that liquidity hoarding has a clear negative externality on the system. Therefore, despite being a defensive measure adopted by banks in times of crises, it ends up weakening the stability of the interbank market. When specifically looking at the role played by the size of the banks, it emerges that the impact of the default of a large bank scales more than proportionally with size. And, as a flip side, contagion improves more when large banks are well-funded than when small banks are the ones with high capital ratios. Put it differently, large banks can perform a stabilizing function as long as they remain healthy.

Along the same lines, Elliott et al. (2014) study how different levels of integration 
and diversification of financial organizations can affect the stability of a financial system. In this model, the initial negative shock to the system takes the form of a (discontinuous) drop in the value of a financial institution and organizations are interdependent because each institution holds shares of other financial entities. Therefore, the market value of one player also depends on the value of the other (interconnected) players. In this context, the level of integration of the financial system is defined as the level of exposure of organizations towards each other; the level of diversification, instead, describes how distributed is the co-ownership across different players. To put it differently, the level of integration describes the depth or extent of organizations' cross-holdings. Instead, the level of diversification expresses the number of organizations directly interacting with one another. The results they obtain are in line with what has been shown in the other contributions: i.e. there exists a contagion window - for both level of diversification and level of integration - where the system is susceptible to contagion. Furthermore, the highest level of instability occurs when both the level of integration and the level of diversification are intermediate. This implies that there needs to be enough (but not too much) integration for a negative shock to the value of one institution to be able to spark the beginning of a defaults cascade. The system must also be diversified enough so that many agents are affected by the losses but not so much that the negative shock is dumped by the system. Elliott et al. (2014) also test how their findings vary when the topology of the (co-ownership) network changes from being an Erdôs-Rényi model (Erdôs and Rényi, 1960) to following different network models. The alternative models the authors used are: a core-periphery network structure, a model where nodes are segregated into different communities, scale-free networks, and networks in which asset values are correlated and portfolio of institutions are overlapping. The results reported by the authors are in line with the ones provided in the other contributions already reviewed in this paper.

The work by Arinaminpathy et al. (2012) can already be included as being part of a series of contributions that explore the role played by the evolution of the financial robustness of each bank in determining how fragile the interbank market is when feedback effects are present. Indeed, in Arinaminpathy et al. (2012), banks' health determined the behavior of the agents in the short-term market. With the same aim in mind, Battiston et al. (2012b) develop a dynamic model of financial robustness where banks are connected in a network of credit relationships. That is, we have a directed weighted graph where edge weights represent interbank assets and liabilities. Financial robustness is defined as the ratio of equity to total assets. This ratio is also used as a proxy for the financial creditworthiness of an agent $i$ and its 
evolution over time is described using a system of stochastic differential equations (SDEs). The goal is to build a model that can capture two different features of the financial network: financial acceleration (i.e., current variations in equity that depend on past variations in equity itself) and interdependence (financial robustness of an agent depends on variations in the robustness of his neighbors).

Financial robustness is modeled as a jump-diffusion process and it is assumed that neighbors of $i$ react whenever they perceive it went through an atypical decrease. Therefore, the external finance premium charged by $i$ 's counterparties does not depend on the absolute value of agent $i$ 's financial robustness but on its (relative) variations when perceived as atypical. Furthermore, the sensitivity of counterparties' reaction and the amplitude of the effect of such reaction are parameters of the model. Sensitivity, amplitude and the size of the variations of the idiosyncratic shocks, all determine the strength of the trend enforcement effect. The higher the ratio of the amplitude over the sensitivity and size of the variations, the more frequently a negative variation in robustness will be followed by another negative variation, implying that the expected time of default of the agent will be shorter. Additionally, in the presence of financial acceleration, the probability of default increases monotonically with the amplitude of neighbors' reactions. Interdependence, instead, is modeled by considering a set of $N$ agents connected through a network of obligations which is described by an exposure matrix which is also the weighted adjacency matrix of the interbank network 10 Out-degree of agent $i$ is going to represent the number of counterparties or neighbors that one bank has and it is a rough measure of the degree of diversification of the agent. The authors also assume that the graph is always regular, i.e. all agents have the same out-degree $k$. To take into account the fact that $i$ 's assets include $j$ 's liabilities and that the value of a bank's portfolio will depend on the value of the assets of its neighbors, a first order linear degree of dependence between the robustness of the agents is assumed. As a consequence, the average effect of the trend reinforcement depends also on the average level of connectivity as determined by $k$. When connectivity is not high (small $k$ ), it is unlikely that a bank hit by a negative shock will be further penalized; but, when connectivity increases, the fluctuation magnitude gets dominated by the magnitude of the effect of the penalty (i.e. the external finance premium that has to be paid). Put it differently, an increasing level of diversification $k$ in the network is beneficial at first, since it will imply smaller fluctuations to the portfolio and hence longer time to default; however, beyond a certain threshold of $k$, whenever a bank suffers a relatively large

\footnotetext{
${ }^{10}$ I.e. the square matrix $W$ whose generic entry $w_{i j}$ represents the weight of the link from $i$ to $j$, and is 0 if banks $i$ and $j$ are not linked in the network.
} 
negative shock, the effect of trend reinforcement will kick in. In terms of probability of default, when financial acceleration is absent, such probability is decreasing with $k$; however, once financial acceleration is introduced, diversification is at some point counterproductive and it increases the probability of default. In terms of systemic risk, higher connectivity implies an increase in the correlation of banks trajectories of robustness. As a result, the probability that several banks fail, conditional to the default of at least one of them, is increasing with $k$. Moreover, when the default of an agent has external effects on its neighbors, the probability of multiple defaults is also growing with $k$. In order to study bankruptcy cascades, the authors assume that when bank $i$ defaults, its neighbors' robustness will be decreased by an amount which is proportional to their relative exposure. This implies that only small- or large-sized cascades will appear in the system. In particular, systemic risk is not in general - monotonically decreasing with risk diversification. The financial system is more likely to be trapped near the threshold at which large cascades occur when the diversification is large, and there exists an optimal level of risk diversification that does not coincide with full diversification.

In a more recent contribution, Roukny et al. (2013) analyze how different factors interplay in determining the stability of the financial system. That is, network topology, banks' characteristics (including financial robustness), capital and liquidity requirements, and types of shocks all contribute in determining the resilience of the interbank market. The model is characterized as follows. A network of $N$ banks is created where links represent lending-borrowing relationships between agents. Two different contagion mechanism are allowed: losses from direct counter-party losses and liquidity shocks due to the adjustment of asset prices after fire-sales. Banks are heterogeneous in their level of robustness - i.e. the ratio of the bank's net worth over the value of its interbank assets - since their initial values are assigned at random and different market structures are tested in the numerical simulations: regular graphs, random graphs, and scale-free graphs. Furthermore, the initial negative shocks can also be of different types: completely random shocks (i.e. a bank is defaulted at random) and targeted defaults, where the hubs are forced into bankruptcy. The main finding of this contribution is that it does not exist an optimal one-fits-all market architecture; instead, the optimal configuration depends crucially on the underlying market conditions. For example, when market liquidity is high, the three different network topologies show a very similar performance in terms in systemic risk; instead, when markets are illiquid, scale-free networks are the most fragile. Furthermore, scale-free graphs can be the most fragile or the most robust market architecture depending on the initial allocation of capital across agents and on the 
correlation between the number of lenders and the number of borrowers each bank has (i.e. the correlation between in- and out-degree). Furthermore, as it has been found in previous studies, when the most connected nodes are also the most robust ones, the market is less fragile. Instead, when attacks are targeted and/or the hubs are not financially robust, the reverse holds.

As far as market stability is concerned, Georg (2013) provides a dynamic model of the interbank market where a central bank is explicitly modeled and its role in improving the stability of the financial system is studied. In this framework, banks can optimize their portfolios of risky investments and adjust their demand/supply of liquidity depending on the stochastic returns their observe on their investments; while the central bank can provide additional liquidity to the system in a setting that is similar to the ones considered in Bluhm et al. (2014); Blasques et al. (2015). Each bank's balance sheet is composed - on the assets side - by risky investments, interbank credits, and excess reserves held before the central bank. On the liabilities side, each bank has deposits, interbank loans, central bank loans, and capital. Banks dynamically determine their portfolio composition and interests are paid/gained on all the lending/borrowing agreements. Liquidity demand and supply are endogenously determined during the evolution of the system since the stochasticity of the returns on the investments and of the level of deposits determine the level of liquidity available/needed by each bank. Banks with excess of liquidity provide credit on the interbank market; while banks with shortage of liquidity request loans either through the interbank market or to the central bank. The central bank provides the additional credit provided that banks have a sufficient collateral. Three different topologies of the interbank market are tested: random graphs (i.e. Erdôs-Rényi null model), scale-free graphs (Barabási and Albert, 1999), and small-world networks (Watts and Strogatz, 1998). Furthermore, the simulations are parametrized as to model two different economic scenarios: a normal time scenario, where most credit is repaid and returns on investments are higher; and a crisis time scenario, where banks suffer larger losses on their investments. The author finds that - in normal times - different network topologies have a similar performance in terms of systemic risk (a result that was also found in Roukny et al. (2013)). However, in times of crisis, network topology do matters. The level of connectivity affect in a non-linear ways the probability of contagion (a result we are familiar with): if the level of connectivity is too low, banks cannot attract enough funding and become illiquid; however, if the level of connectivity is too high the system enters in a contagious regime in which an initial default of a bank can easily cascade to affect the entire financial system. Contagion effects seems to be the largest in random graphs; while 
scale-free graphs are found to be the most resilient. The central bank can have a stabilizing role for the financial system. However, its efficacy depends on the precise network configuration and on the level of collateral requested to obtain liquidity from the central bank. Therefore, even marginal changes in the required levels of collateral can provide strong stabilizing effects on the interbank market. Lastly, the author argues that interbank contagion due to the default of an initial bank has a larger effect on interbank liquidity than an initial common shock that affects more banks at once.

The last contribution we want to focus our attention on, it is the one provided by Montagna and Kok (2013). In this work, the authors develop a multi-agent and multi-layered simulation model where the interbank market is represented as a multi-graph. In particular, three different network layers exist: a network of shortterm interbank loans, a network of long-term interbank loans, and a network that represents the common exposures to financial assets (i.e. the network of overlapping portfolios). Therefore, the combine most of the features we have already observed in other modeling frameworks such as Arinaminpathy et al. (2012); Loepfe et al. (2013); Georg (2013); Bluhm et al. (2014); Blasques et al. (2015). The first two layers are represented as directed weighted graphs; while the latter is represented as a undirected weighted graph. Furthermore, banks' behavior is explicitly modeled and financial institutions can adjust their balance sheets in response to endogenous and/or exogenous liquidity/capital shocks. For example, banks can adapt their exposures so to be able to meet the capital ratio minimum requirements imposed by the policy maker. In particular, banks have to maintain both their risk-weighted capital ratio and their liquidity above two different thresholds. The price of the financial assets is endogenously determined by the model and it depends on the amount of assets - for each given asset category - that are sold during the unfolding of the simulation. Indeed, in order to adjust their capital or liquidity ratios, banks can either reduce their short-term exposures or sell securities, therefore changing the overall market prices and (possibly) causing losses to other agents (financial securities are marked-to-market). Therefore, in this model, authors are able to simulate three kinds of risks: counter-party risk, funding risk and liquidity risk. The model is calibrated using a dataset consisting of a sample of 50 large European Banks for which the following information are known: level of capital, short-term and long-term interbank borrowing, deposits, short-term and long-term interbank loans, aggregate securities holdings, liquidity and the reconstructed risk-weighted-capitalratio. However, bilateral exposures and the amount of individual securities held by each bank are not available in the data. As a consequence, the topologies of the three 
network layers are randomly generated. The main findings of the paper are: first, the contagion effects of an initial shock to one layer can be significantly amplified when all network layers are active, that is, there exist important non-linearities in the way in which bank-specific shocks are propagated throughout the financial system; second, the topology of the networks and the underlying balance sheet positions of the banks matter significantly affect the level of resilience of the financial system; lastly, the presence of common exposures via overlapping portfolios allows the authors to demonstrate the trade-off that exists between risk diversification and financial stability since a decision to diversify that may be optimal at the individual level can end up increasing systemic risk.

\section{Discussion}

This paper has surveyed recent research trying to explain the ways in which bank and market characteristics - such as bank heterogeneity, moral hazard, imperfect information, portfolio optimization, changes in asset prices, and capital and liquidity requirements - interact with network connectivity in determining the stability of the financial system.

We have seen that the level of connectivity influences the probability of the system to remain stable. However, the role played by connectivity depends also on how the structure of the network interacts with additional factors which are specific to the interbank market. Heterogeneity of banks, liquidity and capital requirements, incentives to misbehave and indirect contagion via price changes on common assets are all phenomena that can modify the role played by connectivity within the financial system.

Stylized models, as the ones introduced by Allen and Gale (2000), Babus (2005. 2007), Freixas et al. (2000) and Leitner (2005) all agree that graph incompleteness increases systemic risk and they also stress that having an incomplete network structure is ex-post sub-optimal (Babus, 2005), unless the resources present in the financial system are so scarce that every agent would be better off on its own (Leitner, 2005). May and Arinaminpathy (2010) also find that increasing the level of connectivity is beneficial only when the initial shock has been caused by a default on interbank loans. Instead, the opposite result is found in case of liquidity shocks since a positive feedback effect is going to be generated by the adjustment of asset prices, making the system more fragile when connectivity is increased. However, Babus (2007) also stresses how completeness is just a sufficient condition for stability, not a necessary one. Indeed, most networks can still be incomplete but have 
a low probability of contagion. In addition, Glasserman and Young (2015) show how bounds on the financial systems susceptibility to contagion can be derived even when the exact details of the system's topology are not known.

More complex analytical and numerical models show how the financial system exhibits a robust-yet-fragile property, specifying in a more precise way how connectivity influences stability. In particular, connectivity and size of shocks interacts in determining how a financial system may move from a state of stability to a state of instability in an abrupt way (Gai and Kapadia, 2010; Gai et al., 2011; Amini et al. 2012, Acemoglu et al., 2013; Caccioli et al., 2014) and complete graphs could even be detrimental when the total values of interbank liabilities and claims traded within the network are large (Acemoglu et al., 2013). Furthermore, financial institutions are shown to be interconnected not only via direct lending/borrowing agreements, but also via overlapping portfolios and changes in asset prices (Caccioli et al., 2014. Elliott et al. 2014). Therefore, their financial robustness have to be studied taken also that into account.

Banks diversity is proven to be another source of fragility for the financial system (Iori et al., 2006, Amini et al., 2013, Caccioli et al., 2012, Lenzu and Tedeschi, 2012, Arinaminpathy et al., 2012; Battiston et al., 2012a; Loepfe et al., 2013). As show Iori et al. (2006), increasing connectivity is beneficial only when banks have the same size. Instead, when banks are heterogeneous in size, an increase in connectivity may still lead to less failures but only when interconnectedness is at low levels. Above a given threshold, initial defaults lead to avalanches. A similar conclusion is reached in Loepfe et al. (2013). When shocks are drawn from a fat tailed distribution, an isolated system is better than a connected system. However, whenever link density is low and modularity and size heterogeneity are high, a critical range exists where very small variations in the structure of the network (i.e. the addition or rewiring of few links) can have disproportionate effects in terms of systemic risk.

Banks can also be allowed to vary in terms of individual connectivity, with degree and exposure sequences distributed according to scale-free power law distributions Amini et al. 2013, Lenzu and Tedeschi, 2012). However, also this type of heterogeneity can come to be detrimental for stability. Networks where banks can be heterogeneous in connectivity or size will particularly suffer in case of shocks that directly attack too-big-to-fail or too-connected-to-fail nodes (Caccioli et al., 2012, Loepfe et al., 2013, Georg, 2013; Roukny et al., 2013, Montagna and Kok, 2013). Initial financial robustness can also be heterogeneous across banks. As Battiston et al. (2012a) show, increased connectivity may lead to an increase in systemic risk whenever initial robustness is heterogeneous and many banks are fragile since an 
initial set of defaults will indeed trigger a systemic default.

Furthermore, when shocks are caused by the misbehavior of the agents, the role of connectivity structurally changes. As shown by Brusco and Castiglionesi (2007), when a moral hazard problem is present and banks can invest in a gambling asset, having a more interconnected interbank market increases the extent of contagion in case of bankruptcies. Moreover, when returns from investments are a function of connectivity - the higher the connectivity of the node, the higher the potential gains - and banks can gamble, Castiglionesi and Navarro (2008) show that core-periphery structures emerges.

Imperfect information may also exacerbate contagion by inducing bank runs and fire-sells that also change the effects of connectivity on contagion. For example, Battiston et al. (2012a) demonstrate how imperfect information on the exposures of defaulting banks can lead to bank runs and the role played by connectivity is uncertain in such cases. Indeed, the size of the cascade of defaults is initially decreasing with higher diversification but, after a certain threshold, the dynamics are reversed.

Different tools are available to banks for dealing with uncertainty and imperfect information. For example, peer-monitoring can be used to increase transparency (Blasques et al., 2015) and explicit actions can be taken so that how much each bank is lending/borrowing and to whom it is dealing with is the result of an optimization process where profits are maximized taking into account also for risk and uncertainty (Bluhm et al., 2014; Halaj and Kok Sorensen, 2014).

Prudential regulation has also an impact on the stability of the financial system. Liquidity and capital requirements, by altering the behavior of banks, have several effects on systemic resilience. Cifuentes et al. (2005) show that when contagion spreads also through the asset prices channel, liquidity can be a substitute for connectivity to increase systemic stability. Also, liquidity requirements are more effective than the ones on capital. As far as connectivity is concerned, we have that higher connectivity may lead to an increase of systemic fragility especially when liquidity requirements are low (as also shown in May and Arinaminpathy (2010)). However, for high enough level of interconnectedness, the price contagion channel does entirely disappear. The same result about the non-monotonic effects of connectivity is also obtained by Nier et al. (2007), when we consider the level of capitalization of the system instead of the level of the liquidity requirements.

Additionally, when financial acceleration is introduced (Battiston et al., 2012b), it appears that systemic risk is not - in general - monotonically decreasing with risk diversification. Instead, the optimal level of connectivity does not coincide with full diversification since - at some point - increasing a further increase in connectivity 
raises also the probability of contagion. Furthermore, conditional to the default of at least one bank, the probability of observing a cascade of defaults is increasing with the level of connectivity.

The main conclusion that can be drawn from the papers covered in this survey is that, depending on the assumptions made, average graph connectivity is found to have a strong impact on systemic resilience. Furthermore, such relationship is almost always non-linear, which implies that policy measures have to be carefully implemented in order to be able to decrease the strength and extent of systemic risk.

\section{References}

Acemoglu, D., A. Ozdaglar and A. Tahbaz-Salehi (2013), "Systemic risk and stability in financial networks", NBER Working Paper 18727, .

Afonso, G. and R. Lagos (August 2014), "Trade Dynamics in the Market for Federal Funds", Working Paper 20419, National Bureau of Economic Research.

Allen, F. and A. Babus (2009), "Networks in Finance", in P. Kleindorfer and J. Wind, (eds.), The Network Challenge, Wharton School Publishing, 367-382.

Allen, F. and D. Gale (2000), "Financial contagion", Journal of Political Economy, 108: $1-33$.

Amini, H., R. Cont and A. Minca (2012), "Stress testing the resilience of financial networks", International Journal of Theoretical and Applied Finance, 15: 1250006 (20 pages).

Amini, H., R. Cont and A. Minca (2013), "Resilience to contagion in financial networks", Mathematical Finance, .

Arinaminpathy, N., S. Kapadia and R. M. May (2012), "Size and complexity in model financial systems", Proceedings of the National Academy of Sciences, 109: 18338-18343.

Babus, A. (2005), "Contagion risk in financial networks", In K. Liebscher (ed.), Financial Development, Integration and Stability, Cheltenham, UK: Edward Elgar, pp. 423-440.

Babus, A. (2007), "The formation of financial networks", Tinbergen Institute Discussion Paper No. 2006-093/2, FEEM Working Paper No. 69.2007, Available at SSRN: http://ssrn.com/abstract=939754, 1-32. 
Barabási, A. and R. Albert (1999), "Emergence of scaling in random networks", science, 286: 509-512.

Battiston, S., D. Delli Gatti, M. Gallegati, B. Greenwald and J. E. Stiglitz (September 2012a), "Default cascades: When does risk diversification increase stability?", Journal of Financial Stability, 8: 138-149.

Battiston, S., D. Delli Gatti, M. Gallegati, B. Greenwald and J. E. Stiglitz (August 2012b), "Liaisons dangereuses: Increasing connectivity, risk sharing, and systemic risk", Journal of Economic Dynamics and Control, 36: 1121-1141.

Blanchard, P., C.-H. Chang and T. Krüger (2003), "Epidemic Thresholds on ScaleFree Graphs: the Interplay between Exponent and Preferential Choice", Annales Henri Poincaré, 4: 957-970.

Blasques, F., F. Bräuning and I. Van Lelyveld (2015), "A dynamic network model of the unsecured interbank lending market", Available at SSRN: http://ssrn. com/abstract=2569301, BIS Working Paper No. 491., Available at SSRN: http://ssrn. com/abstract=2569301, 1-55.

Bluhm, M., E. Faia and J. P. Krahnen (2014), "Endogenous banks' networks, cascades and systemic risk", Available at SSRN: http: // papers. ssrn. com/sol3/ papers. cfm? abstract_id=2235520, SAFE Working Paper No. 12., Available at SSRN: http://papers.ssrn.com/sol3/papers.cfm?abstract_id=2235520, $1-76$.

Brusco, S. and F. Castiglionesi (2007), "Liquidity coinsurance, moral hazard, and financial contagion", The Journal of Finance, 62: 2275-2302.

Caccioli, F., T. A. Catanach and J. D. Farmer (2012), "Heterogeneity, correlations and financial contagion", Advances in Complex Systems, 15: 1250058 (15 pages).

Caccioli, F., M. Shrestha, C. Moore and J. D. Farmer (2014), "Stability analysis of financial contagion due to overlapping portfolios", Journal of Banking \& Finance, 46: $233-245$.

Caldarelli, G. (2007), Scale-free networks: Complex webs in nature and technology, Oxford University Press.

Caldarelli, G., A. Chessa, F. Pammolli, A. Gabrielli and M. Puliga (2013), "Reconstructing a credit network", Nature Physics, 9: 125-126. 
Callaway, D., M. Newman, S. Strogatz and D. Watts (2000), "Network robustness and fragility: Percolation on random graph", Physical Review Letters, 85: 54685471.

Castiglionesi, F. and N. Navarro (2008), "Optimal fragile financial networks", Working Paper, .

Catanzaro, M. and M. Buchanan (2013), "Network opportunity", Nature Physics, 9: $121-123$.

Cifuentes, R., G. Ferrucci and H. Shin (2005), "Liquidity risk and contagion", Journal of the European Economic Association, 3: 556-566.

Deloitte and S. F. Partners (2013), "Counterpary risk and CVA survey", Technical Report, Deloitte and Solum Financial Partners.

Diamond, D. W. and P. H. Dybvig (1983), "Bank Runs, Deposit Insurance, and Liquidity", Journal of Political Economy, 91: 401-419.

Eisenberg, L. and T. H. Noe (2001), "Systemic risk in financial systems", Management Science, 47: 236-249.

Elliott, M., B. Golub and M. Jackson (2014), "Financial Networks and Contagion", American Economic Review, 104: 3115-53.

Erdôs, P. and A. Rényi (1960), "On the evolution of random graphs", Magyar Tud. Akad. Mat. Kutató Int. Közl, 5: 17-61.

Freixas, X., B. M. Parigi and J.-C. Rochet (2000), "Systemic Risk, Interbank Relations, and Liquidity Provision by the Central Bank", Journal of Money, Credit and Banking, 32: 611-638.

Gai, P., A. Haldane and S. Kapadia (2011), "Complexity, concentration and contagion", Journal of Monetary Economics, 58: 453-470.

Gai, P. and S. Kapadia (2010), "Contagion in financial networks", Proceedings of the Royal Society A: Mathematical, Physical and Engineering Science, 466: 24012423.

Georg, C.-P. (2013), "The effect of the interbank network structure on contagion and common shocks", Journal of Banking \& Finance, 37: 2216-2228.

Glasserman, P. and H. P. Young (2015), "How likely is contagion in financial networks?", Journal of Banking \& Finance, 50: 383 - 399. 
Gourieroux, C., A. Monfort and E. Renault (1993), "Indirect inference", Journal of Applied Econometrics, 8: S85-S118.

Goyal, S. and F. Vega-Redondo (2007), "Structural holes in social networks", Journal of Economic Theory, 137: 460-492.

Halaj, G. and C. Kok Sorensen (2014), "Modeling emergence of the interbank networks", Available at SSRN: http://ssrn. com/abstract=2397106, , ECB Working Paper No. 1646, Available at SSRN: http://ssrn.com/abstract= 2397106, 1-41.

Haldane, A. G. (2009), "Rethinking the financial network", Speech delivered at the Financial Student Association, Amsterdam, April.

Hasman, A. (2012), "A critical review of contagion risk in banking", Journal of Economic Surveys, forthcoming.

Iori, G., S. Jafarey and F. Padilla (2006), "Systemic risk on the interbank market", Journal of Economic Behavior \& Organization, 61: 525-542.

Jackson, M. O. (2010), Social and Economic Networks, Princeton University Press.

Leitner, Y. (2005), "Financial networks: Contagion, commitment, and private sector bailouts", The Journal of Finance, 60: 2925-2953.

Lenzu, S. and G. Tedeschi (2012), "Systemic risk on different interbank network topologies", Physica A: Statistical Mechanics and its Applications, 391: 43314341.

Loepfe, L., A. Cabrales and A. Sánchez (2013), "Towards a Proper Assignment of Systemic Risk: The Combined Roles of Network Topology and Shock Characteristics", PLoS ONE, 8: e77526.

May, R. M. and N. Arinaminpathy (2010), "Systemic risk: the dynamics of model banking systems", Journal of the Royal Society Interface, 7: 823-838.

May, R. M., S. A. Levin and G. Sugihara (2008), "Complex systems: ecology for bankers", Nature, 451: 893-895.

Mode, C. J. (1971), Multitype branching processes: Theory and applications, volume 34, American Elsevier Pub. Co.

Montagna, M. and C. Kok (2013), "Multi-layered interbank model for assessing systemic risk", Kiel Working Paper 1873, Kiel Working Paper, Kiel. 
Newman, M., "Random graphs as models of networks", in S. Bornholdt and H. G. Schuster, (eds.), Handbook of Graphs and Networks: From the Genome to the Internet, Wiley-VCH, 35-68.

Newman, M. (2010), Networks: An Introduction, Oxford University Press, Inc.

Newman, M., S. Strogatz and D. Watts (2001), "Random graphs with arbitrary degree distributions and their applications", Physical Review E, 64: 026118.

Nier, E., J. Yang, T. Yorulmazer and A. Alentorn (2007), "Network models and financial stability", Journal of Economic Dynamics and Control, 31: 2033-2060.

Roukny, T., H. Bersini, H. Pirotte, G. Caldarelli and S. Battiston (2013), "Default cascades in complex networks: Topology and systemic risk", Scientific Reports, .

Salop, S. C. (1979), "Monopolistic Competition with Outside Goods", The Bell Journal of Economics, 10: 141-156.

Schweitzer, F., G. Fagiolo, D. Sornette, F. Vega-Redondo, A. Vespignani and D. R. White (2009), "Economic networks: The new challenges", Science, 325: 422-425.

Shapley, L. S. (1952), "A value for n-person games", Technical Report, DTIC Document.

Strogatz, S. (2001), "Exploring complex networks", Nature, 410: 268-276.

Upper, C. (2011), "Simulation methods to assess the danger of contagion in interbank markets", Journal of Financial Stability, 7: 111-125.

Watson, H. W. and F. Galton (1875), "On the probability of the extinction of families", The Journal of the Anthropological Institute of Great Britain and Ireland, 4: $138-144$.

Watts, D. (2002), "A simple model of global cascades on random networks", Proceedings of the National Academy of Sciences, 99: 5766-5771.

Watts, D. and S. Strogatz (1998), "Collective dynamics of small-world networks", Nature, 393: 440-442. 